\title{
Economic Analysis of Gas Pipeline Trade Cooperation: A GCC Case Study
}

Bertrand Rioux, Rami Shabaneh and Steve Griffiths 


\section{About KAPSARC}

The King Abdullah Petroleum Studies and Research Center (KAPSARC) is a non-profit global institution dedicated to independent research into energy economics, policy, technology and the environment across all types of energy. KAPSARC's mandate is to advance the understanding of energy challenges and opportunities facing the world today and tomorrow, through unbiased, independent, and high-caliber research for the benefit of society. KAPSARC is located in Riyadh, Saudi Arabia.

This publication is also available in Arabic.

\section{Legal Notice}

(c) Copyright 2021 King Abdullah Petroleum Studies and Research Center ("KAPSARC"). This Document (and any information, data or materials contained therein) (the "Document") shall not be used without the proper attribution to KAPSARC. The Document shall not be reproduced, in whole or in part, without the written permission of KAPSARC. KAPSARC makes no warranty, representation or undertaking whether expressed or implied, nor does it assume any legal liability, whether direct or indirect, or responsibility for the accuracy, completeness, or usefulness of any information that is contained in the Document. Nothing in the Document constitutes or shall be implied to constitute advice, recommendation or option. The views and opinions expressed in this publication are those of the authors and do not necessarily reflect the official views or position of KAPSARC. 


\section{Key Points}

his study assesses the value of developing an interconnected gas grid for Gulf Cooperation Council (GCC) member countries in different counterfactual scenarios consistent with 2018 conditions. It offers the following highlights based on our model and review of European and the Association of Southeast Asian Nations' gas markets:

Expanding the GCC gas grid could yield up to $\$ 3.1$ billion in annualized gains under current conditions by substituting liquid fuels consumed by the power and water sectors with liquified natural gas (LNG).

In a more liberalized and restructured market with competitive end-user gas prices, a GCC gas grid can yield $\$ 1.6$ billion in annualized gains.

Prioritizing LNG over pipeline trade, with Qatar as a major LNG exporter, can reduce - but does not eliminate - the value of the GCC gas grid.

These gains are robust, relative to changes in the opportunity cost of domestic fuel demand.

A gas grid can support the integration of regional fuel prices, eliminate barriers to electricity trade and encourage greater use of the existing GCC power grid. 
N atural gas development across the member states of the Gulf Cooperation Council (GCC) - including Saudi Arabia, the United Arab Emirates (UAE), Qatar, Kuwait, Oman and Bahrain has become a priority for achieving long-term energy security and for supporting economic diversification initiatives (Shabaneh et al. 2020). Natural gas has always played an important part in the energy landscape of the region, primarily in meeting the increasing demand for electricity and supporting the development of energy-intensive industries. However, despite possessing more than $20 \%$ of the world's natural gas proved reserves, the development of natural gas fields in the GCC has historically been secondary to oil fields (Sartori 2019).

The region is currently stepping up its efforts in economic reforms. The versatility of natural gas and its inherent efficiency and environmental benefits can be a key enabler of economic transition plans and long-term sustainable growth. However, low administered gas prices in GCC countries have encouraged an increasing domestic demand while undermining growth in domestic supply. Except for Qatar, GCC member countries either burn oil or import gas - mostly in the form of liquefied natural gas (LNG) - to compensate for the gas shortage.

Considering the similarities between GCC member countries in economic structures and aspirations as well as political systems, this study investigates whether regional gas cooperation, in the form of cross-border infrastructure and trade, can add regional economic value. Energy cooperation is addressed within the objectives under Article 4 of the GCC's charter, which calls for "...coordination, integration and inter-connection between member states in all fields" (Secretariat General of the GCC 2020). However, despite most member countries facing natural gas shortages, scarce efforts have been made regarding an established pipeline gas trade. Nonetheless, factors exist that provide a foundation for GCC countries to redouble their efforts in energy cooperation to establish the region as a preeminent energy hub - now and in future global energy transitions. These include an uncertain outlook for oil, ambitious economic reform agendas, and uncertainty related to the COVID-19 pandemic and how it will shape the future energy landscape.

This study provides an updated version of the KAPSARC Energy Model (KEM). This model is used to investigate integrated fuel, power and water supply across the GCC (Wogan et al. 2019). To our knowledge, no quantitative analysis has been published that addresses the opportunity for GCC gas market integration and trade. To fill this research gap, we investigate the possible evolution of the GCC gas market. We introduce different energy policy scenarios to simulate trade under current regulated end-user fuel pricing policies in individual member states and potential price reform strategies. We also model the economic benefits of expanding the regional gas grid and cross-border pipeline trade and increasing utilization of the existing GCC electricity interconnector for the trade of electric power.

The remainder of this paper is structured as follows. Section 2 provides background information on the GCC's regional context for the development of the gas grid. Section 3 discusses the international development of natural gas markets by considering examples from both Europe and the Association of Southeast Asian Nations (ASEAN). In section 4, we introduce a new gas trade module as an extension of a previous version of the KEM GCC. Finally, section 5 offers a case study on GCC gas trade with expansion of cross-border pipeline infrastructure under different pricing conditions. Concluding remarks and insights for policymakers are provided in section 6 . 


\section{GCC Gas Market Overview}

D iscussions concerning a pan-GCC gas grid date back to the 1990s (NOGA 2017). However, the Dolphin pipeline, which commenced operations in 2007 and transports Qatari gas to the UAE and Oman, is the only cross-border natural gas pipeline in the region. The lack of market price integration and geopolitical constraints are perhaps the two most significant impediments to the development of natural gas cross-border infrastructure investments.

Other types of GCC energy trade infrastructure investments have materialized, in particular the electric power interconnector that connects all six member states. It provides an alternative to transporting fuels across borders, via pipeline or as LNG, by first converting the fuels into electricity in a domestic power plant before export. While the infrastructure exists, discrepancies in administered fuel prices across the countries - and therefore, in the marginal value of electricity production complicates full utilization of the interconnector, and the trade of gas by wire.

Administered gas prices set by the governments of the GCC countries are kept low to promote economic activity and welfare gain. However, this impacts the expansion of natural gas supplies, as prices are lower than the long-term marginal cost of production, specifically from newer sources of non-associated gas. As a result, Kuwait, UAE and Bahrain have installed LNG import facilities in the last decade to cover shortages in domestic gas supplies. Saudi Arabia, however, relies heavily on oil-based power generation, as it has not developed its gas import infrastructure.

The differences in regional fuel prices also discourage cross-border trade. This has impelled Qatar, the region's largest gas exporter and lowest-cost producer, to seek higher prices in international markets for its gas through exports in the form of LNG (Krane and Wright 2014). Regional fuel price misalignment also complicates the integration of the region's power sector and the use of existing interconnector facilities due to fuel subsidy leakages. Wogan et al. (2019) explore this trade barrier through a model that includes constraints that restrict the benefits of administered fuel prices to national power industries and prevents cross-subsidization of fuel supplies between member states through power trade. Their study shows that when allowing such cross-subsidization, the economic benefits that Saudi Arabia loses amount to $\$ 2.2$ billion annually.

Geopolitical tensions have also interrupted bilateral agreements in the past. One example is the case of a pipeline project between Qatar and Kuwait, which was halted by Saudi Arabia's refusal to grant passage through its offshore waters (MEES 2006). Kuwait was thus forced to use a costlier route for meeting its natural gas needs. It installed an LNG import terminal in 2009 with an initial capacity of 5 billion cubic meters per year $(\mathrm{bcm} / \mathrm{y})$. Considering both the short- and long-term costs, transporting LNG from Qatar to Kuwait would cost up to 10 times more on a U.S. dollar per million British thermal unit (\$/MMBtu) basis than using a pipeline. This estimate considers both variable and fixed operating costs of the pipeline, maritime tanker, liquefaction, and regasification facilities, as well as relative processing and transportation yields.

The UAE followed with two (one of $8.2 \mathrm{bcm} / \mathrm{y}$ and one of $5.2 \mathrm{bcm} / \mathrm{y}$ capacity) regasification terminals in 2010 and 2016, respectively. Bahrain was the last GCC member state to launch an LNG regasification terminal with a capacity of $8.2 \mathrm{bcm} / \mathrm{y}$ in 2020 . Table 1 presents a summary of natural gas statistics in the GCC and reveals the variations of gas trade in the region. 
In 2019, interest was renewed in linking the existing national gas grids of the GCC members and of regional neighbors such as Iraq (Malek 2019). Furthermore, there was a shift in state-owned energy companies' business strategies to develop their untapped gas reserves (Shabaneh et al. 2020). A gas pipeline would support integration of gas prices and expose suppliers to new markets, which could motivate investment in undeveloped resources. However, the COVID-19 pandemic has negatively impacted global gas prices. It has also made the gas monetization option of LNG export projects less attractive in the short term and uncertain in the longer term (Ouki 2020).

International experiences in establishing integrated natural gas markets, such as in Europe and North America, reveal benefits to regional cooperation. Achieving such benefits, however, requires overcoming regulatory and legal hurdles that are prerequisites for market liberalization, which are real challenges faced by the GCC countries.

Table 1. GCC natural gas statistics, 2019.

\begin{tabular}{l|c|l|l|c|c|c} 
Country & $\begin{array}{l}\text { Gas reserves } \\
\text { (trillion cubic } \\
\text { meters) }\end{array}$ & $\begin{array}{l}\text { Gas } \\
\text { production } \\
\text { (billion cubic } \\
\text { meters) }\end{array}$ & $\begin{array}{l}\text { Gas } \\
\text { consumption } \\
\text { (billion cubic } \\
\text { meters) }\end{array}$ & $\begin{array}{l}\text { Net pipeline } \\
\text { imports (billion } \\
\text { cubic meters) }\end{array}$ & $\begin{array}{l}\text { Net LNG } \\
\text { imports (billion } \\
\text { cubic meters) }\end{array}$ & $\begin{array}{l}\text { Net imports } \\
\text { (billion cubic } \\
\text { meters) }\end{array}$ \\
\hline Saudi Arabia & 6.0 & 113.6 & 113.6 & 0 & 0 & 0 \\
\hline UAE & 5.9 & 62.5 & 76.0 & 19.5 & -6.1 & 13.4 \\
\hline Qatar & 24.7 & 178.1 & 41.1 & 0 & 0 & -137 \\
\hline Kuwait & 1.7 & 18.4 & 23.5 & 0 & 5.1 & 5.1 \\
\hline Oman & 0.7 & 36.3 & 25.0 & 2.0 & -14.1 & -11.3 \\
\hline Bahrain & 0.1 & 16.9 & 16.9 & 0 & 0 & 0
\end{tabular}

Source: BP Statistical Review 2020.

Note: Minus (-) denotes net exports. 


\section{International Experience in Gas Trade Cooperation}

\section{International trends in gas trading and pricing}

Natural gas continues to be a key element of the global energy mix despite the COVID-19 pandemic of 2020 resulting in a 3.5-4\% reduction in global demand relative to 2019 (Henderson 2020).

Notwithstanding this setback, the average growth in natural gas demand is expected to be approximately $1.5 \%$ per year from 2019 to 2025 , compared with the pre-COVID-19 projection of $1.8 \%$ by the International Energy Agency (IEA 2020). Gas continues to be an attractive industrial feedstock and energy source. This is mainly due to its relatively clean emissions profile, cost competitiveness and increasingly diverse sources of supply, thanks to growth in LNG trade. Based on these factors, most major energy outlooks project the global energy mix share of gas to exceed its current level of $22 \%$ by 2040 (Snam et al. 2019).

As the overall growth in gas consumption resumes, its mode of trade is clearly moving toward LNG. International pipeline gas trade accounted for $22 \%$ of the overall global gas trade in 2019, as opposed to $11 \%$ for LNG (Snam et al. 2019). However, the IEA expects LNG to overtake pipeline gas as the primary mode of international trade before 2030 (IEA 2019b). In 2018, two-thirds of the year-on-year growth in international gas trade was driven by LNG (Snam et al. 2019). Developing countries in Asia are expected to drive continued growth in LNG demand, with their share of total gas demand increasing from $20 \%$ to 40\% between 2018 and 2040 (IEA 2019b).

The upsurge of LNG in global gas markets has also exerted a significant impact on gas pricing trends. Between 2005 and 2019, the share of global gas pricing based on gas-on-gas (GOG) competition increased from $31.4 \%$ to $48.4 \%$, largely at the expense of gas pricing based on oil price escalation (OPE), which declined from $24.3 \%$ to $18.5 \%$ during the same period as reported by the International Gas Union (IGU 2020). This trend is being driven by a rapid increase in global LNG supply at GOG pricing, which reflects an increasing share of LNG spot market procurement (exceeding 30\% in 2019) and European LNG purchases that are entering into traded European gas markets (IGU 2020).

Considering global gas pricing, the COVID-19 pandemic resulted in benchmark global gas prices falling to multi-year lows in 2020. Henry Hub prices reached \$1.9/MMBtu, European gas prices on TTF reached \$1.5/MMBtu and Asian LNG spot prices reached \$2/MMBtu (IEA 2019b). Although short-term gas supply and demand dynamics may depress global gas prices up to 2025 (Henderson 2020), the IEA projects a long-term marginal cost of LNG of $\$ 7.50 / \mathrm{MMBtu}$, with some projects exceeding \$10/MMBtu (IEA 2019b). Hence, gas prices are not expected to follow short-term cost dynamics for an extended period; therefore, long-term energy strategies should not necessarily assume the availability of extremely low-cost imported LNG.

For countries that pursue strategies such as domestic gas development and/or regional pipeline trade, rather than exclusive LNG imports, the global trend in price formation for pipeline gas is toward GOG. However, there is significant regional heterogeneity (IGU 2020). Typically, Middle Eastern domestic gas pricing is regulated according to social and political policies, while pipeline gas imports follow a bilateral monopoly arrangement. Hence, even though regional pipeline gas trade in the Middle East is possible, it would likely incur significant startup friction, given the lack of precedence for market-based gas price formation. 


\section{European trends in gas trading}

Regional cooperation has become one of the mainstays of European energy policy. Recently, it has started to feed into the five dimensions of the European Union's (EU) energy strategy: security of supply, internal energy market security, energy efficiency, climate policy, and research and development (CEEP 2018). Historically, the European gas industry has relied on long-term contracts to develop gas fields and finance long-distance, cross-border pipelines, transmission and distribution systems (Chyong 2019). Long-term contracts are beneficial in de-risking large-scale infrastructure investments.

However, to promote energy efficiency, market integration and improved end-user service, the EU adopted gas liberalization as part of its energy reform policies. This liberalization came in the form of the 1991 Gas Transit Directive, which introduced a competitive market framework to bring supply security and efficiency into the market (Blyhammar et al. 2018). While slow to start, the First and Second Gas Directives of 1998 and 2003, respectively, and the third energy package in 2009 addressed many regulatory and legal hurdles to transforming the EU gas market. This included unbundling gas supply companies, allowing third-party access (TPA) to gas infrastructure and instituting tariff regulation to reflect the costs and operation of the network.

\section{Existing empirical research shows that integration} policies have been successful in Europe, with major gas markets reaching full integration by 2013 (Chyong 2019). This has improved cross-border transmission capacity, which has, in turn, allowed the EU to cope well with gas disruptions (Rodriguez-Gomez, Zaccarelli and Bolado-Lavin 2016). In fact, Europe has seen a significant change in its pricing regimes since 2005, when OPE dominated its gas pricing structure. The market portion based on GOG pricing increased from 15\% in 2005 to $78 \%$ in 2019 (IGU 2020). Spot trading and futures trading increased liquidity in Europe's major gas hubs and shifted contractual pricing of both LNG and pipeline gas imports.

Third-party access to pipelines and underground storage facilities allowed flexibility in the system; moreover, TPA for European LNG import terminals further diversified supply sources. The LNG import capacity increased from $64.3 \mathrm{bcm}$ to $225.6 \mathrm{bcm}$ between 1999 and 2016, accounting for $50 \%$ of the total gas consumption in 2016 (Chyong 2019). The liberalization process has been central to removing destination clauses in LNG contracts in Europe and has driven the shift away from long-term oil-linked contracts.

Despite progress in the liberalization of the gas market and in infrastructure, gas pricing mechanisms are not homogenous across the continent. In Northwest Europe, gas pricing is almost completely based on GOG, with only 5\% of the pricing based on OPE (IGU 2020). Central Europe experienced a massive shift toward GOG pricing, with COG pricing comprising almost $80 \%$ in 2019. The Mediterranean and Southeastern Europe are lagging, where OPE pricing comprises $47 \%$ and $41 \%$, respectively.

As mentioned earlier, the GCC's gas prices are still regulated, and there is no TPA to LNG terminals and pipelines. Integrated gas infrastructure could provide an outlet for surplus regional gas, while further market restructuring can lead to open access to LNG export terminals. Access to existing regasification terminals via the gas grid would also expand import options for members facing gas deficits. 


\section{Southeast Asian trends in gas trading}

In Asia, the developments in gas market integration have not been as smooth as those in Europe. The closest the continent has come to developing a functional gas grid is the Trans-ASEAN Gas Pipeline (TAGP) between ASEAN member countries. Like the GCC, the ASEAN was founded to promote economic, political and security cooperation among its members. The TAGP has been identified as an ASEAN policy priority, as it can bring significant economic and environmental benefits to the region (IEA 2015, 2019a). Other than the TAGP, the organization's vision for cooperation also includes the ASEAN Power Grid (APG) as one of its key energy infrastructure programs (Shi et al. 2019).

In 1997, the ASEAN Vision 2020 outlined plans for constructing new gas pipelines and connecting existing ones to turn the TAGP into a regional gas grid (Sovacool 2009; Fünfgeld 2019). To expedite the development of the TAGP, ASEAN members signed a memorandum of understanding covering issues such as financing options, gas transit rights and contract design, network security, and environmental protection (Sovacool 2009).

By 2015, 13 cross-border ASEAN gas pipelines had been built and four more pipeline projects were under consideration (Anggraeni 2019). However, these pipelines have been used for bilateral trade agreements instead of the initially intended multilateral framework. A multitude of technical, economic, legal, political, social and environmental issues contributed to the stagnation of the TAGP progress (Sovacool 2009; Anggraeni 2019). Such issues are common in multi-stakeholder energy mega-projects (Van de Graaf and Sovacool 2014).
The TAGP has also faced declining ASEAN gas output (ACE 2017), a factor that was not anticipated when the project was first considered. Indonesia's East Natuna gas field, for example, is the largest unexploited gas field in Asia and a key source of natural gas for the TAGP. However, this field contains more than $70 \% \mathrm{CO} 2$, which makes it very expensive and technically challenging to develop (IEA 2015). Consequently, the economics of developing domestic ASEAN gas resources such as this gas field was cast in doubt. The ASEAN therefore shifted its focus to LNG imports (Fünfgeld 2019).

ASEAN LNG imports are expected to increase by more than five times from 2018 to 2030 , with Vietnam and the Philippines becoming new importers (IEA 2020; Kumar and Stern 2020). In October 2019, an import capacity of 36 million tonnes per annum (MMTPA) of LNG was in place, with infrastructure for 75 MMTPA under construction or being developed (The Lantau Group 2019). With the emergence of LNG as a supply source, the key value driver of the TAGP has changed to the trade of imported LNG from global suppliers as opposed to domestically produced gas (Shi et al 2019).

One of the original driving forces of the TAGP was access to natural gas to meet the rapidly growing power demand. As a result of increased LNG imports, the focus of the ASEAN energy infrastructure has shifted to regional power trade via the APG.

The TAGP affair described above shows how the inherent complexity of multilateral gas pipeline projects can impede or halt progress. Like the ASEAN, the GCC sought LNG imports to satisfy regional shortages and continues to encourage member countries to trade in electricity via the regional power interconnector. Unlike the ASEAN, 
however, the GCC shows rapid domestic gas infrastructure development. The region needs to optimize how this new gas infrastructure is utilized and monetized for power, industry and export. A different context means that a GCC gas pipeline may provide more value to GCC member countries than the TAGP provides to ASEAN member countries. Quantifying this benefit is important, as value creation must balance the inevitable and significant coordination costs for the development of a GCC gas grid. 


\section{The KEM GCC Gas Trade Model}

\section{Model overview}

To determine the value of natural gas trade within the GCC, we build on the GCC version of KEM introduced by Wogan et al. (2019). The original work offers a quantitative analysis of the benefits of electricity trade coordination based upon the regional power grid developed and managed by the GCC Interconnector Authority (GCCIA).

The modified fuel supply module optimizes regional production and transportation of oil and gas to meet domestic demand and to export to the international market. The model does not consider endogenous investment in new fuel production capacity. Instead, we focus on the collective optimization of fuel supply costs within the GCC, including natural gas trade by pipeline and LNG trade by maritime tanker. The model includes investments in new cross-border pipelines and natural gas liquefaction and regasification facilities. Investments in maritime tankers are not included. Instead, vessels are considered as available to charter at a long-term marginal cost.

A bottom-up optimization is the standard approach to model infrastructure development for gas supply and trade ( Gabriel et al. 2005; Egging and Gabriel 2006; Holz et al. 2008; Feijoo et al. 2016). The world gas model developed by Nexant Inc. offers an optimization framework for simulating global LNG supply and trade. This model is used by Shi et al. (2019) to assess the possible evolution of ASEAN gas markets. They employ a global framework to capture international trade dynamics and the restructuring of LNG import frameworks when assessing the potential benefits of liberalization within the ASEAN natural gas market.

A few key differences distinguish our approach from those of the gas models referenced above.
First, compared with the work of Shi et al., we do not account for global gas trade dynamics; instead, we focus on the economic value of regional GCC gas trade and disregard the destination of exports outside the GCC. Second, many of these studies focus on fixed gas demand. In this study, however, we take a bottom-up approach to address the GCC power and water supply industries as independent modules that compromise the majority of the regional fuel demand.

On a temporal scale, we characterize gas demand and infrastructure constraints across three seasons: Summer, Fall/Spring and Winter. These are derived from the representation of power demand and supply, which, unlike gas, are broken down into hourly load blocks. Gas demand from all other industrial end users is treated as fixed.

Our model also includes the GCC transmission module developed by Wogan et al. (2019) to represent the optimization of power transmission and trade across the GCC. A complete mathematical description of the extended KEM GCC fuel supply module is provided in Appendix B. Although the model is constructed using a dynamic multi-year framework, for simplicity, we use it in a static single-year framework.

Optimization models often include gas storage activities (e.g., Egging and Gabriel 2006; Feijoo et al. 2016). Matar and Shabaneh (2020) investigate the role of natural gas storage in Saudi Arabia. However, to focus our efforts on the development of a regional gas grid, we exclude the development of storage facilities. To date, there is only one regional gas storage facility in the UAE (CEDIGAZ 2019), with another in development in Saudi Arabia (Sertin 2020). 


\section{Natural gas pricing schemes}

Applying an optimal central planning approach to gas trade and infrastructure planning is equivalent to operating a regional market under perfect competition, with fuel priced at its marginal value. However, in the GCC, gas end-users are subject to different administered fuel prices regulated at the state level. As discussed previously, this complicates efforts to coordinate gas trade.

The partial-equilibrium framework used in KEM to construct the integrated energy market enables it to directly capture price distortions, such as those mentioned above. Each gas-consuming sector and country in the GCC is modeled as an independent optimization agent, and these are solved simultaneously as a single mixed complementarity problem (MCP). Murphy et al. (2019) conduct comprehensive research on measuring the impacts of the types of price controls that can be modeled within an MCP. Several other studies have investigated the impact of price controls using this approach, including administered fuel prices within Saudi Arabia's industrial sectors (Matar et al. 2015; 2017), the role of price caps in China's power sector (Rioux et al. 2017) and China's natural gas supply chain (Rioux et al. 2019).

The MCP approach is also used to model a Nash game to account for the impact on energy prices of imperfect competition by economic agents. These model types have been constructed for North American and European natural gas markets to assess the organization of liberalized gas markets, including the application of market power (Gabriel et al. 2005; Egging and Gabriel 2006; Holz et al. 2008; Feijoo et al. 2016). In this study, we do not consider the application of market power within the GCC gas market, considering the enforcement of strict price regulation. Moreover, several factors confound private sector participation (e.g., crowding out by government investments through state-owned oil and gas companies). Gross and Ghafar (2019) provide a review of such issues while discussing the Gulf region's energy landscape and economic diversification challenges.

In this study, we use the MCP framework to determine how different regional price reform strategies could impact the value of a regional gas grid. Reforms can have a significant influence on regional generation efficiency, the integration of renewables and the transition to a lower carbon economy. However, as discussed by Pollitt (2012) in their review of the liberalization era beginning in the 1980s, a society's willingness and ability to bear the cost of reforms is critical for effective liberalization.

Finally, we utilize the model's ability to capture different gas price coordination and reform levels to understand its influence on power sector integration and trade. Specifically, we take into account the issue of fuel subsidy leakage mentioned earlier. We apply the same constraints as Wogan et al. (2019), which are designed to internalize the benefits of administered fuel prices within national power sectors. In this case, generators are limited to using gas valued at its opportunity cost (e.g., export prices) when trading power to prevent fuel subsidy leakages.

\section{Model calibration}

In our model, we calibrate the coefficients of the fuel supply, power and water sectors to 2018 data for the GCC. The GCC countries include the Kingdom of Saudi Arabia (KSA), the UAE and the Kingdoms of Bahrain (BAH), Kuwait (KUW), Oman (OMN) and Qatar (QAT). Table 2 reports the total natural gas production, consumption (power and water and other industries) and imports and exports (by 
Table 2. Natural gas production, consumption, imports, exports and pricing in the 2018 Calibration scenario (Shabaneh et al. 2020).

\begin{tabular}{l|c|c|c|c|c|c|c} 
Natural Gas (QBtu) & BAH & KSA & KUW & OMN & QAT & UAE & GCC \\
\hline Production & $\mathbf{0 . 5 5 6}$ & $\mathbf{3 . 3 4 9}$ & $\mathbf{0 . 6 5 1}$ & $\mathbf{1 . 5 2 1}$ & $\mathbf{6 . 1 4 3}$ & $\mathbf{2 . 1 9 6}$ & $\mathbf{1 4 . 4 2}$ \\
\hline Consumption & $\mathbf{0 . 5 5 3}$ & $\mathbf{3 . 3 2 7}$ & $\mathbf{0 . 7 9 8}$ & $\mathbf{1 . 0 4 5}$ & $\mathbf{1 . 4 1 0}$ & $\mathbf{2 . 4 9 2}$ & $\mathbf{9 . 6 2 6}$ \\
\hline Power and Water & 0.249 & 2.226 & 0.415 & 0.331 & 0.395 & 1.566 & 5.149 \\
\hline Other & 0.312 & 1.101 & 0.380 & 0.743 & 1.015 & 0.926 & 4.477 \\
\hline Imports & - & - & $\mathbf{0 . 1 5 1}$ & $\mathbf{0 . 0 7 0}$ & - & $\mathbf{0 . 6 7 3}$ & $\mathbf{0 . 8 9 5}$ \\
\hline Pipe & - & - & - & 0.070 & - & 0.638 & 0.708 \\
\hline Tanker (LNG) & - & - & 0.151 & - & - & 0.035 & 0.186 \\
\hline Exports & - & - & - & $\mathbf{0 . 4 7 7}$ & $\mathbf{4 . 2 9 7}$ & $\mathbf{0 . 3 3 0}$ & $\mathbf{5 . 1 0 6}$ \\
\hline Pipe & - & - & - & - & 0.648 & 0.070 & 0.719 \\
\hline Tanker (LNG) & - & - & - & 0.477 & 3.649 & 0.260 & 4.387 \\
\hline $\begin{array}{l}\text { Administered prices } \\
\text { (\$/MMBtu) }\end{array}$ & 3.25 & 1.25 & 3.9 & 3.28 & & 1 & 2.42
\end{tabular}

*Note: For some countries, these are estimates of the internal prices applied to end-users.

Sources: Facts Global Energy, KAPSARC Analysis. Countries: Kingdom of Saudi Arabia (KSA), United Arab Emirates (UAE) Kingdoms of Bahrain (BAH), Kuwait (KUW), Oman (OMN) and Qatar (QAT).

pipeline or tanker) in Quadrillion British thermal units (QBtu) for each country. These values are used to construct our reference calibration scenario. The power and water sector efficiencies, total power demand and other industrial demand are the primary calibration factors used to adjust the model results.

When applying administered prices, fuel allocation quotas are typically enforced to reflect limits on the fuel supply when prices do not reflect scarcity. For this study, we use quotas to limit the supply of fuel provided at subsidized prices within the reference year. While additional fuel may be either sourced locally or imported, we apply fixed quotas for all fuels consumed by the power and water sectors based on reported levels in the reference year. In Table 2, natural gas consumption by the power and water sectors represents the fuel quotas applied under administered pricing. Quotas and administered prices applied to other fuels are listed in Table B.10 of Appendix B.
Considering fuel exports, the international prices for LNG and crude oil are set to \$10/MMBtu (Drahos 2019) and \$71/b (Statista 2020), respectively. We also conduct a sensitivity analysis within the counterfactual scenarios introduced in the next section by reducing the opportunity cost of fuel exports. Considering the volatility of oil prices, the world oil market's response to a change in oil supply or to other factors may lead to fuel exporters assigning a different value to the opportunity cost of domestic demand. For example, Karanfil and Pierru (2020) suggest that for projects with long-term impacts on domestic liquids demand (increasing access to natural gas could be one example), the opportunity cost can range from 15 to $59 \$ / b$.

We can also evaluate different opportunity costs for regional LNG exports from the perspective of a major gas exporter and consumer. Natural gas is projected to increase its share in the regional energy mix; therefore, we draw on recent trends 
in natural gas markets to evaluate the sensitivity of our analysis to LNG export revenues. The 2018 LNG spot prices fell to under \$6/MMBtu (Alex 2019), with the level staying below $\$ 5 / \mathrm{MMBtu}$ during the COVID-19 pandemic.

Table 3 provides a breakdown of the fixed capital (capex) and variable operating (opex) expenditures of natural gas transportation and processing. Transportation costs are expressed in U.S. dollars per million British thermal units per km per year (\$/MMBtu-km). Expected facility lifetime assumptions are used to calculate the annualized capital cost of infrastructure investments included in the model. A $6 \%$ interest rate is used to calculate discounted investments costs for pipeline and LNG processing equipment. This is the same interest rate used by Matar et al. (2015) to represent Saudi government investments in oil and gas infrastructure projects.

Appendix B provides additional specifications and descriptions of the sources used to configure the regional gas grid, power transmission, liquefaction and regasification capacities and costs. This includes the existing Dolphin pipeline connecting Qatar, the UAE and Oman and the master gas system of Saudi Arabia that links the eastern, central and western regions. Appendix $B$ also provides calibration data for the KEM power and water sectors modules, as originally presented by KAPSARC (2015) and documented online (KAPSARC 2020).

Table 3. Capital (capex) and operating (opex) expenditures of natural gas pipeline and LNG activities.

\begin{tabular}{l|c|c|c|c|c} 
Type & $\begin{array}{c}\text { Units (2018 } \\
\text { dollars) }\end{array}$ & Capex & Opex & Losses \\
\hline $\begin{array}{l}\text { Pipeline } \\
\text { (onshore) }\end{array}$ & $\$ / \mathrm{km} / \mathrm{MMBtu} / \mathrm{year}$ & 0.005 & 0.00001 & $0.003(\% / \mathrm{km})$ & 35 \\
\hline $\begin{array}{l}\text { Pipeline } \\
\text { (offshore) }\end{array}$ & $\$ / \mathrm{km} / \mathrm{MMBtu} / \mathrm{year}$ & 0.01 & 0.00001 & $0.003(\% / \mathrm{km})$ & 35 \\
\hline $\begin{array}{l}\text { LNG tanker } \\
\text { Floating } \\
\text { liquefaction plant }\end{array}$ & $\$ / \mathrm{kmMB} / \mathrm{MMBtu} / \mathrm{year}$ & - & 0.00011 & $0.00015(\% / \mathrm{km})$ & - \\
\hline $\begin{array}{l}\text { Regasification } \\
\text { plant }\end{array}$ & $\$ / \mathrm{MMBtu} / \mathrm{year}$ & 16.4 & 0.65 & $10 \%$ & 20 \\
\hline
\end{tabular}

Sources: Pipeline capital expenditure (capex) cost - The World Bank (2013) (Appendix B.2). LNG tanker operating expenditure (opex) costs - Timera Energy (2018). Capex and opex of liquefaction and regasification facilities - Songhurst (2019), processing losses - Tavares et al. (2018). 


\section{Case Study: GCC Gas Trade}

or our case study, we develop different counterfactual scenarios - calibration, existing technologies, current policies, and liberalized - for the model calibration to revisit regional gas trade in 2018. These scenarios and their key assumptions are summarized in Table 4. In each counterfactual scenario, gas suppliers can invest in new liquefaction, regasification and LNG transportation infrastructure. These scenarios are then run both with and without investment in the GCC gas grid to assess the added economic value.

Oil and gas production capacities, the total demand for power and water, and other exogenous industrial gas demand are held constant. GCC countries can use the existing GCC power interconnector but are restricted from trading in power generated from fuel allocated under administered prices.

First, we investigate the expansion of the GCC gas grid under regional policies, targeting increased utilization of gas by the existing mix of power and water sector technologies (Appendix B, Table B.7 and Table B.8). This is the Existing tech scenario, which proposes the estimated value of a new gas grid based on the current technological configuration of the GCC fuel, power, and water sectors. In this scenario, the sectors do not invest in new generation equipment; however, units can be reconfigured to burn gas instead of oil or refined products. Existing Dolphin pipeline contracts are honored and quotas for crude oil and its products at administered prices are removed, prioritizing the transition to gas.

Next, we consider counterfactual scenarios from the perspective of restructuring the technologies and fuel demand of the power and water sectors. ${ }^{1}$ We start with a counterfactual scenario in which current administered fuel pricing policies and 2018 fuel quotas for oil and gas are applied (Current policies). In this scenario, power producers can procure fuel above their quotas, for example, to participate in cross-border power trade without fuel subsidy leakages.

Table 5 lists the relative changes in the objective value (fuel supply, power and water sectors) scenarios under Existing tech and Current policies. Changes are shown in the context of the 2018 Calibration, as well as with respect to the same counterfactual scenarios without pipeline investments to isolate the economic gain from building out the gas grid. We also include changes in total capex for cross-border pipeline and LNG infrastructure, gas demand by the power and water industries and LNG exports. The supply-demand balances in each scenario are summarized in Appendix C (Table C.1).

Table 4. List of model scenarios.

\begin{tabular}{l|c|l}
\multicolumn{1}{c|}{ Scenario } & $\begin{array}{c}\text { Power and water sector } \\
\text { investments }\end{array}$ & \multicolumn{1}{c}{ Fuel price reform } \\
\hline Calibration & No & No \\
\hline Existing technologies & No & $\begin{array}{l}\text { Fuel quotas under administered prices are removed and } \\
\text { power and water sectors optimize fuel mixes under the existing } \\
\text { technology configuration }\end{array}$ \\
\hline Current policies & Yes & $\begin{array}{l}\text { Current administered fuel prices are applied but users can } \\
\text { purchase fuel at liberalized prices above their quotas }\end{array}$ \\
\hline Liberalized & Yes & Prices are fully liberalized
\end{tabular}


Table 5. Change in objective value, capital expenditures of pipeline and LNG in billion \$; change in the gas demand of the power and water sectors; LNG exports in QBtu and percentage terms.

\begin{tabular}{l|c|c|c|c|c|c|c} 
& \multicolumn{2}{|c|}{ Relative to 2018 Calibration } & \multicolumn{4}{|c|}{ Relative to counterfactual scenario without pipeline investments } \\
$\begin{array}{l}\text { Billion \$ } \\
\text { Scenario }\end{array}$ & $\begin{array}{c}\text { Objective } \\
\text { value }\end{array}$ & $\begin{array}{c}\text { Gas } \\
\text { demand } \\
\text { QBtu* }\end{array}$ & $\begin{array}{c}\text { Objective } \\
\text { value }\end{array}$ & $\begin{array}{c}\text { Pipeline } \\
\text { capex }\end{array}$ & $\begin{array}{c}\text { LNG } \\
\text { capex }\end{array}$ & $\begin{array}{c}\text { Gas } \\
\text { demand } \\
\text { QBtu (\%) }\end{array}$ & $\begin{array}{c}\text { LNG } \\
\text { Exports } \\
\text { QBtu (\%) }\end{array}$ \\
\hline $\begin{array}{l}\text { Existing } \\
\text { tech }\end{array}$ & 4.1 & $\begin{array}{c}1.50 \\
(29 \%)\end{array}$ & 3.13 & 1.90 & -4.94 & $\begin{array}{c}0.75 \\
(13 \%)\end{array}$ & $\begin{array}{c}-1.45 \\
(-32 \%)\end{array}$ \\
\hline $\begin{array}{l}\text { Current } \\
\text { policies }\end{array}$ & 12.6 & $\begin{array}{c}-0.75 \\
(-15 \%)\end{array}$ & 0.52 & 0.17 & -2.77 & -0.03 & -0.11 \\
$(-1 \%)$ & & & & $(-2 \%)$
\end{tabular}

*Total demand in 2018 (Calibration) was 9.63 QBtu with 5.15 QBtu used by power and water sectors.

Source: KAPSARC analysis.

\section{GCC Gas trade: Existing technologies}

Under the Existing technologies scenario, an annual economic gain of $\$ 4.1$ billion is achieved, relative to the 2018 Calibration. When optimizing the regional fuel mix, gas is prioritized for domestic use. This increases the demand by 1.5 QBtu, or $29 \%$. GCC crude oil exports increase by 1.0 million barrels of oil per day (MMb/d), which, in turn, increases regional oil export revenues, primarily for Saudi Arabia and Kuwait. $^{2}$

However, a large portion of these gains, $\$ 3.13$ billion, can only be achieved when the GCC gas grid is expanded to reduce regional gas supply costs. Otherwise, the higher cost of transporting gas to all GCC regions experiencing shortages offsets the economic gains (i.e., freeing crude oil for export). This illustrates how regional policies aimed at increasing the utilization of gas in the power and water sectors could benefit from the expansion of the GCC gas grid.

Cross-border pipeline and LNG tanker trade are depicted in Figure 1 for the Calibration, Existing tech, and Current policies scenarios. The horizontal axes represent the source country, while the vertical axes represent the destination. Under Existing tech, gas demand growth is covered by Qatar via a trunk line to Saudi Arabia (1.7 QBtu) and Kuwait (0.54 QBtu). This also offsets LNG shipments in the Calibration scenario. ${ }^{3}$ Overall, LNG trade within the GCC and exports to the rest of the world decline by $32 \%$.

The value generated by the expansion of the GCC gas grid can be attributed to two sources. First, optimizing energy transportation logistics has a cost saving effect - in particular, a reduction in more expensive LNG tanker shipments within the GCC. While not shown in Figure 1, if the gas grid is not developed, about 1.1 QBtu of regional LNG tanker trade is required to satisfy the increased demand. Second, the development of the gas grid increases the accessibility and demand for gas by 0.75 QBtu, freeing approximately $0.8 \mathrm{MMb} / \mathrm{d}$ of crude oil for export. A more detailed breakdown and discussion of the gains achieved per sector and per country is provided in Appendix C. 
Figure 1. Pipeline and tanker shipments under Calibration (a), Existing tech (b) and Current policies (c) scenarios in QBtu.

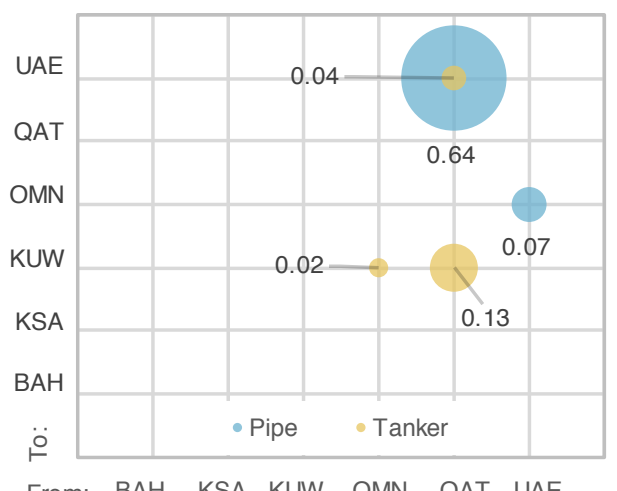

(a)

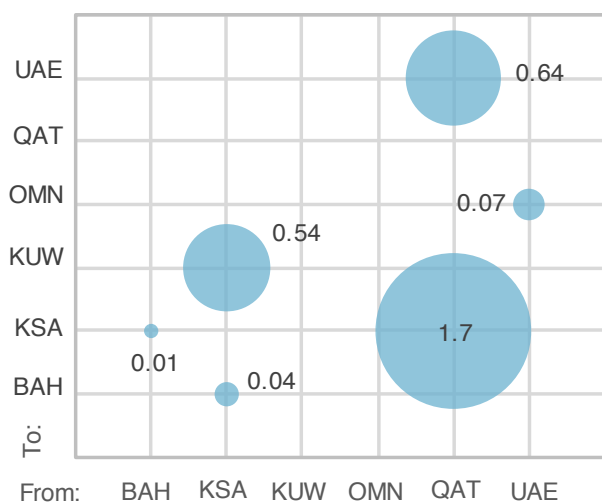

(b)

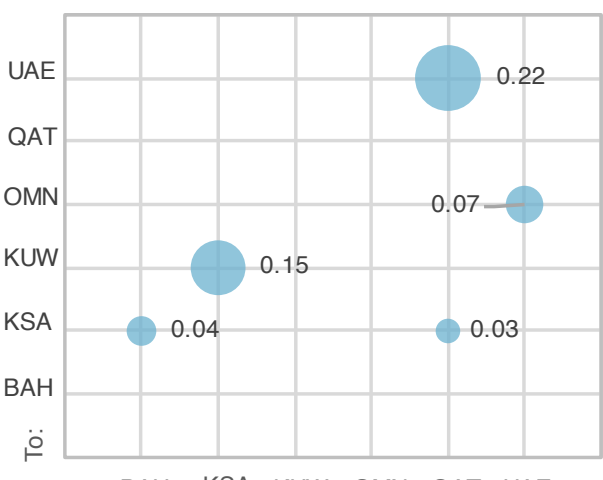

From: BAH KSA KUW OMN QAT UAE

(c)

Countries: Kingdom of Saudi Arabia (KSA), United Arab Emirates (UAE) Kingdoms of Bahrain (BAH), Kuwait (KUW), Oman (OMN) and Qatar (QAT).

Source: KAPSARC analysis.

In total, $\$ 1.9$ billion of new cross-border pipeline capital is developed. This is around $2.4 \%$ of the discounted capital development cost of all GCC non-associated gas projects estimated for the next 30 years. These projects have an estimated total value of $\$ 79.5$ billion, according to UCube (Rystad 2019).

These gains should be sensitive to the value assigned to fuel export revenues for both oil (\$72/bbl) and gas (\$10/MMBtu). To address this, we run a sensitivity analysis on the opportunity cost of domestic fuel demand, discounting both oil and gas export prices by $50 \%$ to $\$ 36 / \mathrm{b}$ and $\$ 5 / \mathrm{MMBtu}$, respectively. We find that the devaluation of lost LNG revenues (from increased domestic gas demand) offsets the lower opportunity cost of increasing crude oil exports. In fact, the annual economic gain for pipeline investments increases slightly to $\$ 3.27$ billion. This outcome will depend on the relative opportunity costs of oil and gas; assuming a premium on oil, a gas grid would provide significant annual gains with an increase in regional gas demand. 


\section{GCC Gas trade: Current policies}

In the Current policies scenario, we consider the optimal adjustment of the technologies being used by the power and water sectors in 2018, assuming that producers had sufficient time to invest. Investments are presented in Appendix C (Figure C.1).

Relative to the 2018 Calibration scenario, economic gains of $\$ 12.6$ billion could have been achieved by reducing the fuel demand through the development of new technologies (including renewables and nuclear) and converting existing open cycle turbines to more efficient combined cycle turbines. This makes approximately $0.29 \mathrm{MMb} / \mathrm{d}$ of crude oil available for export. Overall, the Current policies scenario offers a 0.75 QBtu (15\%) reduction in gas demand relative to Calibration. This enables 12 MMTPA of additional LNG exports, and Saudi Arabia and Bahrain to become net exporters to Kuwait, replacing some LNG exports by Qatar. Qatar, in turn, continues to sell gas to the UAE and Oman (Figure C1).

Under these fuel pricing conditions expansion of the GCC gas grid provides US $\$ 0.52$ billion of annualized gains. As in the Existing tech scenario the gas grid substitutes more expensive maritime LNG trade, and offsets US $\$ 2.77$ billion of total capital invested in new liquefaction terminals. Given the lower overall gas demand, pipeline investments fall by an order of magnitude to US $\$ 0.17$ billion. There is no significant change in oil exports, with existing policies continuing to allocate liquid fuels at competitive administered prices.

Applying the same sensitivity analysis as before, i.e., lowering the opportunity cost of crude oil and LNG exports by $50 \%$, increases the gains from expansion of the pipeline grid to US\$0.86 billion. Under these conditions the power and water sectors increase the consumption and trade of gas at more competitive liberalized prices, above their administered quotas from oil and gas.

This scenario shows how the value of the gas grid is sensitive both to changes in the regional fuel supply and demand balances, but also continued domestic fuel pricing policies. How these factors play out over the next decade will impact potential trade flows. If GCC members individually achieve gas self-sufficiency through production expansion, technology improvements, and/or prioritizing liquid fuel consumption the grid may deliver less value.

On the other hand, new opportunities could emerge through industrial demand growth and further substitution of liquid fuel for gas, strategic infrastructure developments (e.g., LNG processing hubs), and trade to neighboring countries of the GCC. Dynamic forward-looking analysis is left for future exercise. We investigate the impact of price liberalization and regional reforms on fuel switching, as well as strategic LNG trade, in the following sections.

\section{Strategic gas trade: Qatar LNG scenario}

Trade strategies for LNG by GCC members can have an impact on gas grid development. In the ASEAN market, the development of LNG import facilities substituted new regional gas production, which influenced how the gas grid was used. While LNG imports could support gas supplies in some GCC countries, the gas can easily be sourced within the GCC, given the abundance of regional production. Although it is more expensive than pipelines, LNG offers greater trade flexibility. 
We set up a new scenario called Existing tech Qatar LNG, in which Qatar secures a contract for supplying a minimum of 3 MMTPA of LNG to Kuwait, based upon recently announced agreements (Hagagy, 2020). Qatar also chooses not to build new cross-border pipelines, prioritizing regional demand for its liquefaction facilities.
Table 6 shows the changes in economic gains, demand, capital expenditure and gas exports for the Qatar LNG scenario. LNG trade contracts reduces the value of the gas grid to $\$ 1.65$ billion, a decline of $47 \%$ relative to the US $\$ 3.13$ billion under Existing tech.

Table 6. Results for the Qatar LNG scenario. Change in objective value, pipeline, and LNG capex in billion \$; gas demand of the power and water sectors; LNG exports in QBtu.

\begin{tabular}{l|c|c|c|c|c|c|c} 
& \multicolumn{2}{|l|}{$\begin{array}{l}\text { Change relative to } 2018 \\
\text { Calibration }\end{array}$} & \multicolumn{3}{|c|}{ Change relative to counterfactual scenario without pipeline investments } \\
$\begin{array}{l}\text { Billion \$ } \\
\text { Scenario }\end{array}$ & $\begin{array}{c}\text { Objective } \\
\text { value }\end{array}$ & $\begin{array}{c}\text { Gas demand } \\
\text { QBtu* }(\%)\end{array}$ & $\begin{array}{c}\text { Objective } \\
\text { value }\end{array}$ & $\begin{array}{c}\text { Pipeline } \\
\text { capex }\end{array}$ & $\begin{array}{c}\text { LNG } \\
\text { capex }\end{array}$ & $\begin{array}{c}\text { Gas demand } \\
\text { QBtu (\%) }\end{array}$ & $\begin{array}{c}\text { LNG exports } \\
\text { QBtu (\%) }\end{array}$ \\
\hline $\begin{array}{l}\text { Existing tech } \\
\text { Qatar LNG }\end{array}$ & 2.91 & $1.26(25 \%)$ & 1.65 & 0.99 & -4.94 & $0.51(8 \%)$ & $-0.45(-10 \%)$
\end{tabular}

Source: KAPSARC analysis.

Figure 2. Cross-border pipeline and tanker flows under Current Tech Qatar LNG.

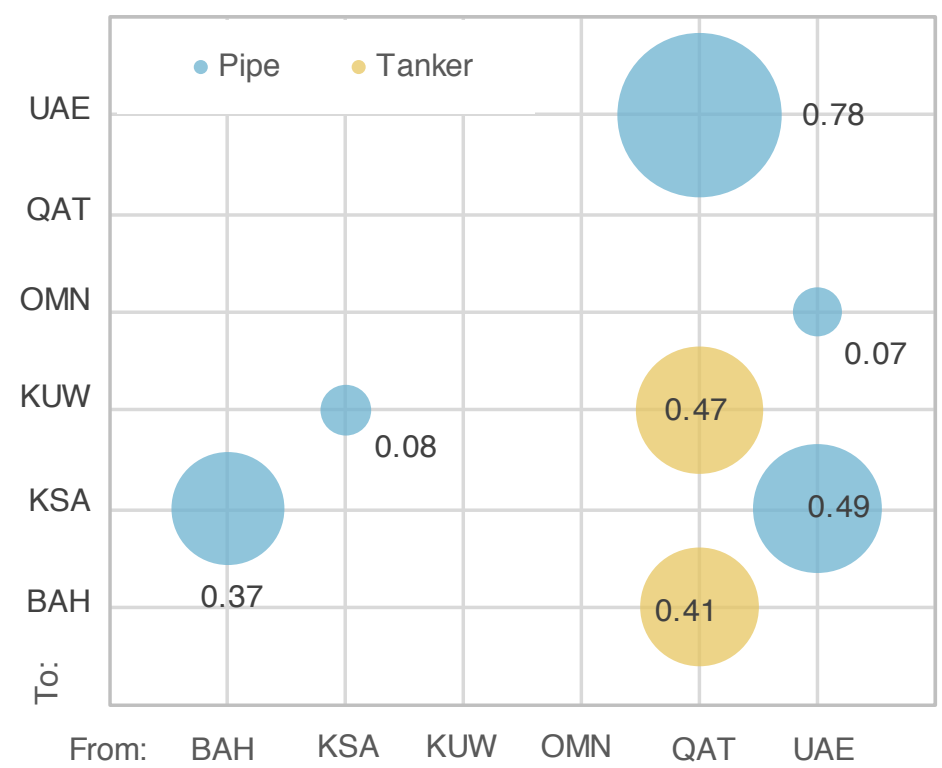

Countries: Kingdom of Saudi Arabia (KSA), United Arab Emirates (UAE), Kingdoms of Bahrain (BAH), Kuwait (KUW), Oman (OMN) and Qatar (QAT).

Source: KAPSARC analysis. 
As shown in Figure 2, Qatar increases LNG trade with Kuwait and Bahrain. Kuwait imports 0.47 QBtu, which is equivalent to 9.5 MMTPA - more than three times the value in the proposed contract. While Qatar does not build a new pipeline, Saudi Arabia and to a smaller extent Kuwait import gas via new pipelines connected to the UAE and its exiting Dolphin pipeline with Qatar. Bahrain also builds a link to Saudi Arabia supplied by LNG imported through existing regasification facilities.

\section{Economic gains from regional gas trade: Liberalized scenarios}

Finally, we explore the role of the gas grid in the transition to a more Liberalized fuel market. This represents a longer-term view of the price reform and industrial restructuring in the gas trade. Both the power and water sectors now purchase gas (and other liquid fuels) at a nominal price determined by the regional supply networks (pipeline and LNG). This provides gas consumers with the opportunity cost of oil and gas exports.
Table 7 shows the change in fuel prices under the Liberalized scenario. Prices are more than double the administered levels applied in 2018 (Current Policies) in many GCC countries. In this scenario, prices reflect the netback of LNG export prices, less liquefaction and transportation costs. Next, we set up a Liberalized price cap scenario to address the impact of gas prices on the competitiveness of end-users. In this case, GCC members coordinate regional gas prices so that they are bound to regional marginal production costs, not the opportunity cost of exporting LNG.

In Appendix A.3, we explain how complementary slackness is used to represent this hybrid pricing scheme within our integrated MCP model. In sum, a discount is determined for regional prices that reflects the differences between the opportunity cost of gas (netback of export prices) and the regional production cost. For example, we use $\$ 4 / \mathrm{MMBtu}$ as a representative long-term marginal production cost for the region, as reported by Matar and Shabaneh (2019). We then set the maximum reference price in Qatar as the major gas supply hub in the region. This is close to the highest administered gas prices applied in Kuwait (Table 7).

Table 7. Average industrial natural gas prices for each GCC country in \$/MMBtu. For the Liberalized scenario, we show prices with and without expansion of the gas grid.

\begin{tabular}{l|c|c|c|c|c|c|c} 
Scenario & BAH & KSA & KUW & OMN & QAT & UAE & Average \\
\hline Current policies & 3.28 & 1.25 & 3.90 & 3.28 & 1.00 & 2.42 & 2.18 \\
\hline Liberalized & 7.07 & 7.20 & 7.29 & 7.01 & 7.01 & 7.05 & 7.11 \\
\hline Liberalized price cap & 4.08 & 4.21 & 4.33 & 3.83 & 4.00 & 3.93 & 4.07
\end{tabular}

Countries: Kingdom of Saudi Arabia (KSA), United Arab Emirates (UAE), Kingdoms of Bahrain (BAH), Kuwait (KUW), Oman (OMN) and Qatar (QAT).

Source: KAPSARC analysis. 
Table 8 shows the changes in economic value, gas demand, capital expenditure, and gas exports under the two Liberalized scenarios. In the first scenario, the demand declines by 1.22 QBtu (24\%), as higher price incentive generators transition to alternative power technologies. These include $68 \mathrm{GW}$ of solar photovoltaic (PV), $14 \mathrm{GW}$ of wind, and more efficient reverse osmosis water desalination (see Appendix C). The reduced gas demand from the transition to renewables limits the benefits of pipeline investments to only $\$ 0.12$ billion.

In the Liberalized price cap scenario, there is less incentive to develop renewables, with the power and water sectors prioritizing gas over other liquid fuels. The introduction of new technologies (e.g., a nuclear plant in the UAE) and improved efficiencies result in a redistribution of the gas demand across the GCC. In this scenario, the gas grid provides $\$ 1.61$ billion in annual gains by offsetting energy transportation cost, including 0.09 QBtu of LNG tanker shipments to Kuwait.

Without the expansion of the gas grid, regions with gas shortages face prices exceeding \$6/MMBtu because of the higher cost of transporting gas as LNG. However, rather than importing gas as $L N G$, regions with no pipeline access to other GCC countries choose to import power from those that have a gas surplus. This involves significant expansion of the regional power interconnector, with the GCC electricity trade reaching 137 terawatthours (TWh) versus 27 TWh with the gas grid, an $80 \%$ reduction. Although more cost effective than shipping the gas directly as LNG, investments in new transmission lines ( $\$ 7$ billion) and power capacity ( $\$ 3$ billion) are more capital intensive than building new pipelines (\$2.6 billion).

Another approach to analyzing a Liberalized scenario with lower fuel prices is reducing the opportunity cost of fuels. By applying the same sensitivity analysis presented earlier, the economic gains of the grid in both the Liberalized scenarios (with and without a cap) increase to $\$ 2$ billion. Under the lower opportunity cost of LNG, GCC member states increase demand for gas, and therefore the cost savings from increased pipeline trade.

Table 8. Results for Liberalized scenarios. Change in objective value, pipeline and LNG capex in billion US\$; gas demand of the power and water sectors; LNG exports in QBtu.

\begin{tabular}{l|c|c|c|c|c|c|c} 
& \multicolumn{2}{|c|}{ Relative to 2018 Calibration } & \multicolumn{2}{|c|}{$\begin{array}{l}\text { Relative to the same counterfactual scenario without cross-border pipeline } \\
\text { investments }\end{array}$} \\
$\begin{array}{l}\text { Billion \$ } \\
\text { Scenario }\end{array}$ & $\begin{array}{c}\text { Objective } \\
\text { value }\end{array}$ & $\begin{array}{c}\text { Gas demand } \\
\text { QBtu* }(\%)\end{array}$ & $\begin{array}{c}\text { Objective } \\
\text { value }\end{array}$ & $\begin{array}{c}\text { Pipeline } \\
\text { capex }\end{array}$ & $\begin{array}{c}\text { LNG } \\
\text { capex }\end{array}$ & $\begin{array}{c}\text { Gas demand } \\
\text { QBtu (\%) }\end{array}$ & $\begin{array}{c}\text { LNG exports } \\
\text { QBtu (\%) }\end{array}$ \\
\hline Liberalized & 21.1 & $\begin{array}{c}-1.22 \\
(-24 \%)\end{array}$ & 0.12 & 0.17 & -2.99 & $\begin{array}{c}0.13 \\
(3.5 \%)\end{array}$ \\
\hline $\begin{array}{l}\text { Liberalized } \\
\text { price cap }\end{array}$ & 18.7 & $\begin{array}{c}0.01 \\
(0.2 \%)\end{array}$ & 1.61 & 1.07 & 0.00 & $\begin{array}{c}-0.12 \\
(-2 \%)\end{array}$ & -0.21 \\
$(2.8 \%)$ & $(-4 \%)$
\end{tabular}

Source: KAPSARC analysis. 


\section{Power sector integration}

Coordinated price reforms can also influence the integration of other infrastructure, such as the GCC power interconnector. As reported in the Liberalized price cap scenario, the GCC gas grid offers cost savings by offsetting power trade. It does so by supplying GCC states with fuel to localize power production using the available efficient generation capacity. However, in an economically efficient system, the power grid can also enable coordinated trade among member countries by incentivizing countries to buy electricity from available efficient generation units in neighboring states.

However, discrepancies in administered fuel prices across the GCC can significantly distort or obstruct such benefits. Wogan et al. (2019), identify fuel subsidy leakages as a major trade barrier.
Figure 3 shows the regional power trade between GCC countries under the Current policies, Liberalized and Liberalized price cap scenarios. When combining the regional gas grid with the integration of end-user prices (both Liberalized scenarios), power trade across the interconnector increases significantly compared with the 7.3 TWh traded under Current policies. In the Liberalized and Liberalized price cap scenarios, trade increases to 20.5 TWh and 27.1 TWh, respectively. In the former, trade flows in both directions among several countries in all seasons and all hourly demand blocks (aggregated in the figure), representing a broader utilization of the interconnector. This reflects diversification in the power generation mix - including more renewables - with the interconnector providing regional load balancing services.

Figure 3. Regional power trade (all seasons) for Current policies (a), Liberalized (b) and Liberalized price cap (c) scenarios in TWh.

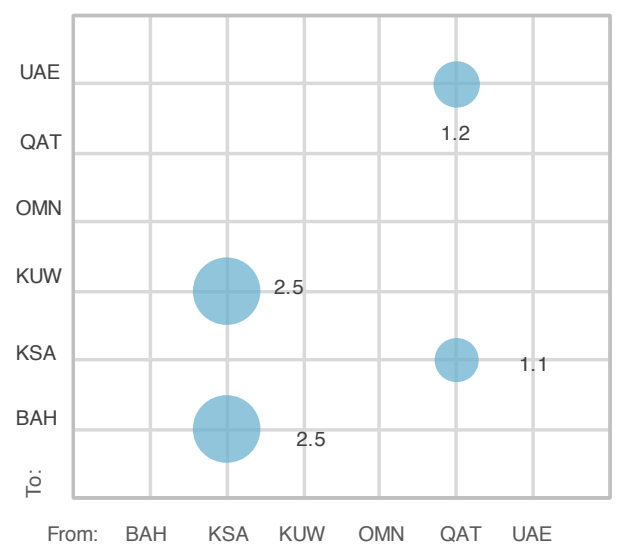

(a)

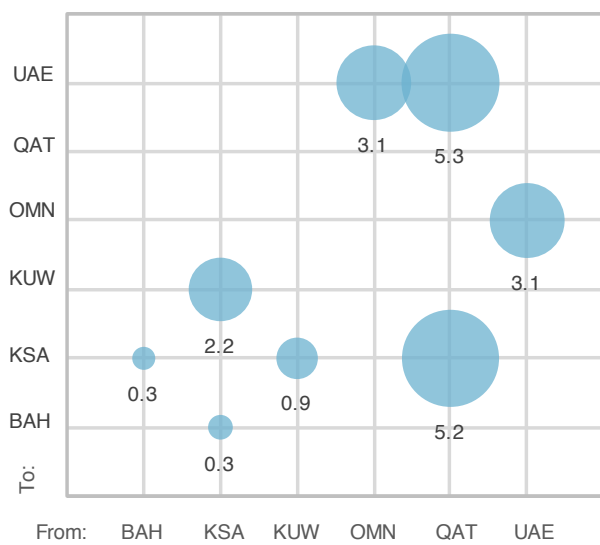

(b)

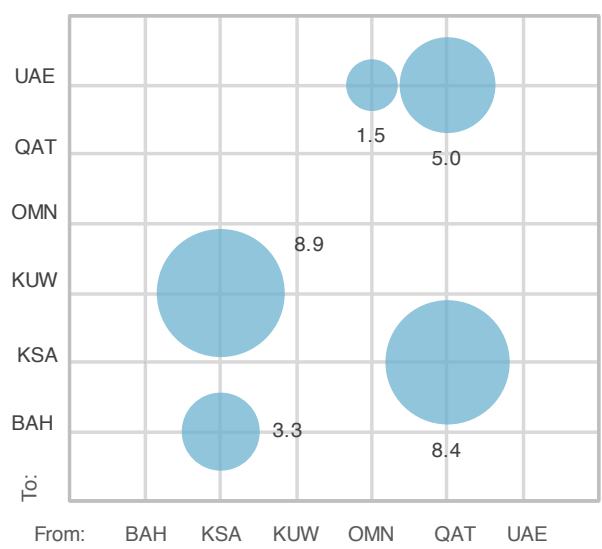

(c)

Countries: Kingdom of Saudi Arabia (KSA), United Arab Emirates (UAE), Kingdoms of Bahrain (BAH), Kuwait (KUW), Oman (OMN) and Qatar (QAT). Source: KAPSARC analysis. 


\section{Conclusion}

N atural gas pipeline infrastructure can foster and sustain regional energy trade and cooperation, providing both economic benefits and regional energy security. However, other countries and regions' experiences show that realizing such benefits involves deep market reforms. Moreover, experiences vary across regions. While gas market liberalization helped Europe achieve an integrated gas network, the ASEAN market still has some way to go before the potential of the proposed TAGP network is realized. The growth in availability and flexibility of LNG from the international market is an important factor in both Europe and the ASEAN. However, the evolution of the regulatory and market structure in Europe facilitated efficient use and trade of gas via the pipeline network.

This study investigates the value that the GCC region can generate from developing a gas grid, vis-à-vis LNG by tanker and gas to wire. We quantify the value of a trans-GCC gas grid under different regional policy assumptions and price reform strategies based on conditions reported in 2018 . We find that the economic benefit from cross-border gas pipeline trade is based on two key factors. First, cost savings associated with energy transportation are realized, including a shift to pipeline versus more expensive LNG shipments or capital-intensive expansion of cross-border power trade. Second, increased oil export revenues via oil-to-gas substitution to avoid the high opportunity cost of domestic oil consumption.

In an Existing tech (for power and water production) scenario, gas is prioritized for domestic production, freeing crude oil for export. In this scenario, a GCC gas grid could have provided US\$3.1 billion in economic gains. A continuation of current pricing policies limits the substitution of liquid fuels for gas and significantly reduces the overall value of expanding pipeline trade. Under a restructured fuel pricing regime, with liberalized pricing of gas that prioritizes the competitiveness of gas end-users across GCC energy sectors (Liberalized price cap scenario), we estimate $\$ 1.65$ billion in annual gains from an expanded pipeline grid. These results are robust, relative to the opportunity cost applied to domestic oil and demand based on fuel export prices. Most of the gains reported in this paper are from optimizing transportation costs and infrastructure investments.

In the two Liberalized scenarios, the integration of regional fuel prices also helps eliminate barriers (i.e., fuel subsidy leakages) to electricity trade. This encourages greater use of the existing GCC power grid. Such gains are not unique to the region, with the IEA highlighting power trade as a policy priority for the ASEAN market. The GCCIA (2019) and Wogan et al. (2019) reported expected gains of up to $\$ 1$ billion per year from increased utilization of the electricity interconnector.

Liberalization can also better address changes in the supply and demand balance. This ensures that gas is delivered to where it provides the greatest value, which accommodates possible changes in the direction of trade along the grid. Although not addressed in this analysis, integrated gas prices would signal changes in the seasonal gas demand and support the operation of natural gas storage facilities.

Past experiences show that non-commercial aspects such as geopolitical dimensions will play a significant role in GCC gas trade. For example, scenarios in which Qatar prioritizes LNG trade eliminate a significant portion of the value generated by the gas grid. The value offered by the gas grid also declines significantly when accounting for changes in gas supply and demand balances, such 
as restructuring of gas demand by the power and water sectors. Under Current policies (administered fuel prices in 2018), continued liquid fuel demand and lower gas demand reduces the value of the grid to $\$ 500$ million.

In summary, this study shows the economic potential of an integrated GCC gas market. As the ASEAN situation demonstrates, however, multiple sociopolitical challenges that may exceed those that are purely technoeconomic may need to be overcome to successfully complete such a megaproject. Accordingly, this study may offer a foundation to regional policymakers for assessing how GCC countries can leverage regional natural gas coordination for long-term viability while facing an uncertain global energy transition.
Specifically, we consider the value of natural gas for current domestic industrial use and for avoiding the opportunity cost of burning liquid fuels for electricity. We do not, however, consider fuel switching by other industrial sectors, energy transition opportunities such as LNG bunkering for clean maritime transport or blue hydrogen (i.e., natural gas reforming with carbon capture) for global export. Changes in supply and demand will also impact gas trade. As the region continues to cultivate its natural gas resource base, these opportunities may prove valuable and make the short-term development of a GCC gas grid an important regional asset in the years ahead. 


\section{Endnotes}

${ }^{1}$ Note that in the scenarios with power sector investment, we include new facilities that have been approved or completed since 2018. These include the 5.6 GW Barakah nuclear plant, the $0.95 \mathrm{GW}$ CSP and the $2.4 \mathrm{GW}$ coal plant in the UAE, and PV plants in the UAE, KSA, Oman and Qatar (1.78, 0.3, 0.5 and 0.7 GW, respectively).

${ }^{2}$ We do not explicitly model refining activities; therefore, we do not account for potential export revenues from a reduction in refined products consumption. This would have increased the economic gains relative to the Calibration scenario.

${ }^{3}$ In 2018, Qatar and Oman were the major exporters of LNG to Kuwait. Kuwait also imported LNG from countries outside the GCC. However, in the model, we make the simplifying assumption that these are substituted by LNG supplies from the GCC.

${ }^{4}$ Tankers have the flexibility of being leased for exports to consumers outside the GCC; this is not possible for fixed pipelines. Embedding the sunk cost of existing GCC tanker capacity into the transport cost reflects the value gained from the flexibility of chartering tankers for trade outside the GCC. 


\section{References}

ASEAN Centre for Energy (ACE). 2017.

"The 5th ASEAN Energy Outlook 20152040." CBU International Conference

Proceedings. Jakarta. https://aseanenergy.org/ the-5th-asean-energy-outlook/.

Alex, Froley. 2019. "Global Spot LNG Prices

Slide below \$6/MMBtu." Independent

Commodity Intelligence Services. https://

www.icis.com/energy-connections/2019/03/

global-spot-Ing-prices-slide/.

Anggraeni, Silvia Dian. 2019. "Trans-Asean Gas Pipeline (Tagp) Cooperation and the Projection of Indonesia's Energy Security." Asia Pacific Journal of Advanced Business and Social Studies 5 (1): 14151. https://doi.org/10.25275/apjabssv5i1ss13.

Blyhammar, Annette Berkhahn, Yvonne Fuller, and Michael Kruse. 2018. "Analysis of the Proposed Gas Directive Amendment." Arthur D. Little. https:// www.adlittle.com/sites/default/files/viewpoints/adl_ review_gas_directive_amendment.pdf.

CEDIGAZ. 2019. "UNDERGROUND GAS STORAGE IN THE WORLD - 2019 STATUS." CEDIGAZ INSIGHTS 35. https://www.cedigaz. org/wp-content/uploads/Cedigaz-Insights-nº-35Overview-of-underground-gas-storage-in-theworld-2018.pdf.

Central Europe Energy Partners (CEEP). 2018. "Cross-Border Energy Cooperation in Central Europe: Towards Flexible, Secure and Sustainable Regional Energy Markets." https://www.ceep.be/ www/wp-content/uploads/2018/11/CEDE-2018policy-papper.pdf.

Chyong, Chi Kong. 2019. "European Natural Gas Markets: Taking Stock and Looking Forward." Review of Industrial Organization 55 (1): 89-109. https://doi.org/10.1007/s11151-019-09697-3.
Drahos, Nikolai. 2019. "LNG Spot Price Forecasting and the Futures Curve." The Oxford Institute for Energy Studies. https://www.oxfordenergy.org/ wpcms/wp-content/uploads/2019/06/LNG-SpotPrice-Forecasting-and-the-Futures-Curve-NG147.pd.

Egging, Rudolf G., and Steven A. Gabriel. 2006. "Examining Market Power in the European Natural Gas Market." Energy Policy 34 (17): 2762-78. https:// doi.org/10.1016/j.enpol.2005.04.018.

Feijoo, Felipe, Daniel Huppmann, Larissa Sakiyama, and Sauleh Siddiqui. 2016. "North American Natural Gas Model: Impact of Cross-Border Trade with Mexico." Energy 112: 1084-95. https://doi. org/10.1016/j.energy.2016.06.133.

Fünfgeld, Anna. 2019. "ASEAN Energy Connectivity: Energy, Infrastructure and Regional Cooperation in Southeast Asia." The Indonesian Quarterly 46 (January): 315-45.

Gabriel, Steven A., Jifang Zhuang, and Supat Kiet. 2005. "A Large-Scale Linear Complementarity Model of the North American Natural Gas Market." Energy Economics 27 (4): 639-65. https://doi. org/10.1016/j.eneco.2005.03.007.

Global Gas \& Oil Network. 2020. "Global Fossil Infrastructure Tracker." http://ggon.org/fossil-tracker/.

Graaf, Thijs Van de, and Benjamin K. Sovacool. 2014. "Thinking Big: Politics, Progress, and Security in the Management of Asian and European Energy Megaprojects." Energy Policy 74 (C): 16-27. https:// doi.org/10.1016/j.enpol.2014.06.027.

Gross, Samantha, and Adel Abdel Ghafar. 2019. "The Shifting Energy Landscape and the Gulf Economies Diversification Challange." https:// www.brookings.edu/wp-content/uploads/2019/12/ FP_20191210_gcc_energy_ghafar_gross.pdf. 
Henderson, James. 2020. "Quarterly Gas Review : Short and Medium Term Outlook for Gas Markets." 2020. https://www.oxfordenergy.org/wpcms/ wp-content/uploads/2020/07/Quarterly-Gas-ReviewIssue-10.pdf.

Holz, Franziska, Christian von Hirschhausen, and Claudia Kemfert. 2008. "A Strategic Model of European Gas Supply (GASMOD)." Energy Economics 30 (3): 766-88. https://doi.org/10.1016/j. eneco.2007.01.018.

International Energy Agency (IEA). 2015. "WEO2015 Special Report: Southeast Asia Energy Outlook." https://webstore.iea.org/weo-2015-specialreport-southeast-asia-energy-outlook.

\section{- - . 2019a. "Establishing Multilateral Power}

Trade in ASEAN." https://www.oecd.org/publications/ establishing-multilateral-power-trade-in-asean0c4a10e5-en.htm.

- - . 2019b. "World Energy Outlook 2019." Paris. https://webstore.iea.org/world-energy-outlook-2019.

- - . 2020. "Gas 2020." Paris. https://www.iea.org/ reports/gas-2020/2020-meltdown.

International Gas Union (IGU). 2020.

"Wholesale Gas Price Survey - 2020 Edition." International Gas Union World Gas Conference Papers. Vol. 4. https://www.igu.org/resources/ wholesale-price-survey-2020-edition/.

KAPSARC. 2015. "The KAPSARC Energy Model for Saudi Arabia." https://www.kapsarc.org/wp-content/ uploads/2016/11/KEM-SA_documentation_v9.16.pdf.

- - . 2020. "KAPSARC Energy Model: A

Framework for Energy Economics." https://kapsarc. github.io/kem/web/software.html.
Karanfil, Fatih, and Axel Pierru. 2020. "The Opportunity Cost of Domestic Oil Consumption for an Oil Exporter: Illustration for Saudi Arabia." March. https://doi.org/10.30573/KS--2020-DP05.

Krane, Jim, and Steven Wright. 2014. "Qatar 'Rises above' Its Region: Geopolitics and the Rejection of the GCC Gas Market." The London School of Economics and Political Science 35 (35): 2-22. http://eprints.Ise.ac.uk/55336/1/__Ise.ac.uk_storage_ LIBRARY_Secondary_libfile_shared_repository_ Content_Kuwait Programme_Krane_2014.pdf.

Kumar, Maggie, and Jonathan Stern. 2020. "Gas Industry Reform and the Evolution of a Competitive Gas Market in Malaysia." https://doi. org/10.26889/9781784671570.

Malek, Miriam. 2019. "Saudi Arabia-GCC Gas Pipeline Studies to Commence Within Weeks: Falih." S\&P Global Platts, April 8. https://www.spglobal. com/platts/en/market-insights/latest-news/naturalgas/040819-saudi-arabia-gcc-gas-pipeline-studiesto-commence-within-weeks-falih.

Matar, Walid, Frederic Murphy, Axel Pierru, and Bertrand Rioux. 2015. "Lowering Saudi Arabia's Fuel Consumption and Energy System Costs Without Increasing End Consumer Prices." Energy Economics 49: 558-69. https://doi.org/10.1016/j. eneco.2015.03.019.

Matar, Walid, Frederic Murphy, Axel Pierru, Bertrand Rioux, and David Wogan. 2017. "Efficient Industrial Energy Use: The First Step in Transitioning Saudi Arabia's Energy Mix." Energy Policy 105 (July): 80-92. https://doi.org/10.1016/j.enpol.2017.02.029.

Matar, Walid, and Rami Shabaneh. 2019. "Viability of Seasonal Natural Gas Storage in the Saudi Energy System." SSRN Electronic Journal, no. 19-418. February. https://doi.org/10.2139/ssrn.3485992. 
MEES. 2006. "Kuwait's Qatar Natural Gas Import Plan Shelved For Foreseeable Future." http:// archives.mees.com/issues/300/articles/12246.

Murphy, Frederic, Axel Pierru, and Yves Smeers. 2019. "Measuring the Effects of Price Controls Using Mixed Complementarity Models." European Journal of Operational Research 275 (2): 666-76. https://doi. org/10.1016/j.ejor.2018.11.051.

National Oil and Gas Authority, Bahrain (NOGA). 2017. "Opportunities for Pan GCC Natural Gas Grid." Regional Gas Industry Issues and Opportunities. Muscat.

Ouki, Mostefa. 2020. "MENA - Could Intra-Regional Gas Trade Be Refocused as a Result of the Ongoing Global Crisis?" https://www.oxfordenergy. org/wpcms/wp-content/uploads/2020/05/MENACould-intra-regional-gas-trade-be-refocussed-as-aresult-of-the-ongoing-global-crises-.pdf.

Pollitt, Michael G. 2012. "The Role of Policy in Energy Transitions: Lessons from the Energy Liberalisation Era." Energy Policy 50: 128-37. https:// doi.org/https://doi.org/10.1016/j.enpol.2012.03.004.

Rioux, Bertrand, Philipp Galkin, Frederic Murphy, Felipe Feijoo, Axel Pierru, Artem Malov, Yan Li, and Kang Wu. 2019. "The Economic Impact of Price Controls on China's Natural Gas Supply Chain." Energy Economics 80: 394-410. https://doi. org/10.1016/j.eneco.2018.12.026.

Rioux, Bertrand, Philipp Galkin, Frederic Murphy, and Axel Pierru. 2017. "How Do Price Caps in China's Electricity Sector Impact the Economics of Coal, Power and Wind? Potential Gains from Reforms." Energy Journal 38: 63-75. https://doi. org/10.5547/01956574.38.Sl1.brio.
Rioux, Bertrand, Abdullah Al Jarboua, Frederic Murphy, and Axel Pierru. 2020. "Implementing Alternative Pricing Policies in Economic Equilibrium Models Using the Extended Mathematical Programming Framework," no. March: 1-32. https:// doi.org/10.30573/KS--2020-MP01.

Rystad. 2019. "Rystad Energy UCube." September. https://www.rystadenergy.com/energy-themes/ oil--gas/upstream/u-cube/.

Sartori, Nicolo. 2019. "GCC: Rapid Change in the Energy Sector." https://www.eni.com/static/en-IT/ world-energy-magazine/gulf-vision.html\#slide12.

Secretariat General of the GCC. 2020. "About GCC: The Charter." https://www.gcc-sg.org/en-us/ AboutGCC/Pages/Primarylaw.aspx.

Sertin, Carla. 2020. "Samsung Engineering Wins \$1.85bn Aramco Gas Storage Contract." Oil \& Gas Middle East. https://www.oilandgasmiddleeast.com/ products-services/35917-samsung-engineeringwins-185bn-aramco-gas-storage-contract\%0AMay be worth mentioning $\% 0 \mathrm{~A}$.

Shabaneh, Rami, Bertrand Rioux, and Steve Griffiths. 2020. "Can Cooperation Enhance Natural Gas Utilization in the GCC?" Riyadh. https://www. kapsarc.org/research/publications/can-cooperationenhance-natural-gas-utilization-in-the-gcc/.

Shi, Xunpeng, Hari Malamakkavu Padinjare Variam, and Yifan Shen. 2019. "Trans-ASEAN Gas Pipeline and ASEAN Gas Market Integration: Insights from a Scenario Analysis." Energy Policy 132 (May): 83-95. https://doi.org/10.1016/j.enpol.2019.05.025.

Snam, IGU, and BCG. 2019. "Global Gas Report 2019." https://media-publications.bcg.com/SNAM2019-GGR.pdf. 
Songhurst, Brian. 2019. "Floating LNG Update - Liquefaction and Import Terminals." https:// www.oxfordenergy.org/wpcms/wp-content/ uploads/2019/09/Floating-LNG-Update-

Liquesfaction-and-Import-Terminals-NG149.pdf.

Sovacool, Benjamin K. 2009. "Energy Policy and Cooperation in Southeast Asia: The History, Challenges, and Implications of the Trans-ASEAN Gas Pipeline (TAGP) Network." Energy Policy 37 (6): 2356-67. https://doi.org/10.1016/j.enpol.2009.02.014.

Statista. 2020. "Average Annual Brent Crude Oil Price from 1976 to 2020." https:// www.statista.com/statistics/262860/ uk-brent-crude-oil-price-changes-since-1976/.

Tavares, Felipe Botelho, Thomas Mitro, Nicolas Maennling, and Perrine Toledano. 2018. "Manual for the Open LNG Regasification Model." http://ccsi. columbia.edu/files/2018/03/LNG-Import-ModelManual-CCSI-2018.pdf.

The Lantau Group. 2019. "Role of Gas in Ensuring Energy Sustainability in South East Asia."
The World Bank. 2013. "Regional Gas Trade Projects in Arab Countries." 1 (76114). https:// documents.worldbank.org/en/publication/documentsreports/documentdetail/692191468276383876/ main-report.

Timera Energy. 2018. "Deconstructing LNG Shipping Costs." https://timera-energy.com/ deconstructing-Ing-shipping-costs/.

Tuomiranta, Arttu, Muniba Abdul Aziz, and Hosni Ghedira. 2017. "Zoning Study for Deployment of Photovoltaic Power Stations in the UAE Zoning Study for Deployment of Photovoltaic Power Stations in the United Arab Emirates." https://doi. org/10.13140/RG.2.2.35826.61122.

Wogan, David, Frederic Murphy, and Axel Pierru. 2019. "The Costs and Gains of Policy Options for Coordinating Electricity Generation in the Gulf Cooperation Council." Energy Policy 127 (November): 452-63. https://doi.org/10.1016/j. enpol.2018.11.046. 


\section{Appendix A. KEM GCC gas trade module}

Table A.1. Model components.

$\begin{array}{ll}\text { Indices } & \\ \boldsymbol{a} & \text { Gas production asset } \\ \boldsymbol{c}, \boldsymbol{c c} & \text { Country } \\ \boldsymbol{f} & \text { Fuel: } \text { crude oil, natural gas }\left(\mathrm{CH}_{4}\right) \\ \boldsymbol{r}, \boldsymbol{r} \boldsymbol{r} & \text { Regions within each country } \\ \boldsymbol{s} & \text { Season }\end{array}$

\section{Variables}

$\mathbf{z}$

$d_{f, r, s}$

Objective value

$e_{f, r, s}$

Fuel demand set by power and water industries. Exogenous to the fuel supplier's problem

$f_{r}^{l i q}, f_{r}^{r e g}$

Fuel exports in season $s$

$q_{a, r, s}$

Building activity for daily liquefaction and regasification capacities

$l_{f, r, s}^{\text {in }}, l_{f, r, s}^{\text {out }}$

Fuel Production in season $s$

$t_{f, r, r r, s}^{p i p e}, t_{f, r, r r, s}^{\text {tank }}$

Tanker shipment loading/unloading (e.g., liquefaction/regasification) of fuel

$u_{f, r, r r, s}$

Pipeline and tanker transport of fuel $f$ in season $s$

\section{Coefficients}

$\boldsymbol{C}_{\boldsymbol{a}, \boldsymbol{f}, \boldsymbol{r}}$

Pipeline building activity

$Q_{a, f, r}$

Marginal production cost for fuel $f$ from asset $s$ in region $r$

$F_{r}^{l i q}, F_{r}^{r e g}$

Existing daily production capacity for fuel $f$ from asset $a$

$K^{\text {liq }}, K^{\text {reg }}$

Existing daily liquefaction and regasification capacities

$K_{f, r, r r}^{p i p e}$

Liquefaction and regasification capex

$N_{s}$

Pipeline capex

$O_{f}^{\text {in }}, O_{f}^{\text {out }}$

Number of days in season $s$

$\boldsymbol{O}_{f, r, r r}^{\text {pipe }}, \boldsymbol{O}_{f, r, r r}^{\text {tank }}$

Tanker loading/unloading (e.g., liquefaction/regasification) marginal cost

$\boldsymbol{P}_{f, s}$

Pipeline and tanker marginal transport cost for fuel $f$ from region $r$ to $r r$

$\boldsymbol{U}_{f, r, \boldsymbol{r r}}$ International fuel price (seasonal)

$Y_{f, r, r r}^{\text {pipe }}, Y_{f, r, r r}^{\operatorname{tank}}$

Existing daily pipeline capacity for fuel $f$ from region $r$ to $r r$

$Y_{f}^{\text {in }}, Y_{f}^{\text {out }}$

Pipeline and tanker transportation yields

Tanker shipment yield for loading/unloading (e.g., liquefaction/regasification) 


\section{A.1. Fuel supplier's optimization problem}

$$
\begin{aligned}
\max z=\sum_{f, r, s} e_{f, r, s} P_{f, s}- & \sum_{a, f, r, s}\left(q_{a, f, r, s} C_{a, f, r, s}\right)-\sum_{f, r, r r . s}\left(t_{f, r, r r, s}^{\text {pipe }} O_{f, r, r r}^{\text {pipe }}+t_{f, r, r r, s}^{\text {tank }} O_{f, r, r r}^{\text {tanker }}+u_{f, r, r, s} K_{f, r, r r}^{\text {pipe }}\right) \\
& -\sum_{r}\left(\sum_{f, s}\left(l_{f r, s}^{\text {in }} O_{f}^{\text {in }}+l_{f r, s}^{\text {out }} O_{f}^{\text {out }}\right)+f_{r}^{\text {liq }} K^{l i q}+f_{r}^{r e g} K^{r e g}\right)
\end{aligned}
$$

Subject to

$$
\begin{array}{ll}
Q_{a, f, r}-q_{a, r, s} / N_{s} \geq 0 & \perp \alpha_{a, f, r, s} \geq 0 \\
F_{r}^{l i q}+f_{r}^{l i q}-\sum_{f=C H_{4}} l_{f, r, s}^{\text {in }} / N_{s} \geq 0 & \perp \rho_{r, s}^{\text {liq }} \geq 0 \\
F_{r}^{r e g}+f_{r}^{r e g}-\sum_{f=C H_{4}} l_{f, r, s}^{\text {out }} / N_{s} \geq 0 & \perp \rho_{r, s}^{r e g} \geq 0 \\
U_{f, r, r r}+u_{f, r, r r, s} \geq t_{f, r, r r, s}^{\text {pipe }} / N_{s} & \perp \lambda_{f, r, r r, s} \geq 0 \\
l_{f, r}^{\text {in }}-e_{f, r, s}-\sum_{r r} t_{f, r, r r, s}^{\text {tank }} \geq 0 & \perp \sigma_{f, r, s} \geq 0 \\
\sum_{r r} t_{f, r r, r, S}^{\text {tank }} Y_{f, r r, r}^{\text {tank }} Y_{f}^{\text {out }}-l_{f, r}^{\text {out }} \geq 0 & \perp \varphi_{f, r, s} \geq 0 \\
& \perp \pi_{f, r, s} \geq 0
\end{array}
$$

$$
\left(\sum_{a} q_{a, f, r, s}+l_{f, r, s}^{\text {out }}\right) Y_{f, r, r}^{\text {pipe }}+\sum_{r r}\left(t_{r r, r, s}^{\text {pipe }} Y_{f, r r, r}^{\text {pipe }}-t_{r, r r, s}^{\text {pipe }}\right)-l_{f, r, s}^{\text {in }} / Y^{\text {in }} \geq d_{f, r, s}
$$

Equation block (1) defines the optimization problem of the fuel supplier's problem for all GCC member states defined by the different regions $r$. That is, maximize export revenues less operating and annualized capital expenses for the production and transportation of all fuels $f$ between regions $r$ and $r r$ in each season $s$, subject to constraints (A1.1) to (A1.7). As a convention, the marginal values or dual variables associated with each constraint are given on the right-hand side as orthogonal complementarity conditions. This means that when the primal constraint is binding, the corresponding dual variable can take on a non-negative value; otherwise, it is equal to zero. These are used to construct the optimality conditions of the fuel supplier's problem in the following section.

All indices, variables and coefficients used are listed and defined in Table A.1. The first term in equation (1) defines the export revenues from the export of fuel $e_{f, r, s}$ to the international market at fixed price $P_{f, s}$. The second term subtracts the variable production cost $C_{a, f, r, s}$ of fuel production $q_{a, f, r, s}$ from each linear supply activity indexed by $a$. The next term subtracts the aggregate variable transport $\operatorname{cost} O_{f, r, r r}^{p i p e}$ of pipeline shipments $t_{f, r, r r, s}^{\text {pipe }}$ between regions, the maritime tanker shipments $t_{f, r, r r, s}^{t a n k}$ and the annualized capital cost $K_{f, r, r}^{p i p e}$ of building a new pipeline capacity $u_{f, r, r, s}$. Finally, we subtract the variable operating costs $O_{f}^{\text {in }}$ and $O_{f}^{\text {out }}$ of loading fuel into $l_{f r, s}^{\text {in }}$ and unloading from $l_{f r, s}^{\text {out }}$ maritime tankers, as well as the related annualized capital costs of $K^{\text {liq }}$ and $K^{\text {reg }}$ of building new liquefaction $b_{r}^{\text {liq }}$ and regasification $b_{r}^{r e g}$ facilities.

Constraint (A1.1) uses the existing daily production capacity for each linear supply activity $Q_{a, f, r}$ as the upper bound on the seasonal fuel production, divided by the number of days in each season $N_{s}$. Constraints (A1.2), (A1.3) and (A1.4) set the total capacity available for liquefaction, regasification and pipeline transportation, respectively, including both existing and newly built infrastructure for each activity. 
Equation (A1.5) sets the upper bound of exports and regional maritime transport as the amount of fuel loaded into tankers in each region. Meanwhile (A1.6) requires the total amount of fuel unloaded from tankers to be less than the incoming tanker shipment, including regional transportation and unloading (e.g., regasification) yields, $Y_{f, r r, r}^{\text {tank }}$ and $Y_{f}^{\text {out }}$, respectively.

The final demand constraint for fuel delivered by pipeline is provided in (A1.7). The total production plus fuel unloaded from tankers (accounting for the intraregional delivery yield $Y_{f, r, r}^{\text {pipe }}$ ), plus net pipeline flows into each region, less fuel loaded into tankers (accounting for loading yields, e.g., liquefaction) must exceed the seasonal fuel demand $d_{f, r, s}$.

\section{A.2. Optimality conditions analysis of competitive gas pricing}

Table A.2. Dual variables from the fuel supplier's constraints in equation block (1).

\begin{tabular}{|c|c|c|c|}
\hline$\alpha_{a, f, r, s}$ & \multicolumn{3}{|c|}{ Scarcity premium on linear fuel supply activities } \\
\hline$\rho_{r}^{l i q}$ & \multicolumn{3}{|c|}{ Scarcity premium on liquefaction } \\
\hline$\rho_{r}^{r e g}$ & \multicolumn{3}{|c|}{ Scarcity premium on regasification } \\
\hline$\lambda_{r, r r}$ & \multicolumn{3}{|c|}{ Scarcity premium on pipeline transportation } \\
\hline$\sigma_{f, r, s}$ & \multicolumn{3}{|c|}{ Marginal value on tanker loading and fuel exports } \\
\hline$\varphi_{f, r, s}$ & \multicolumn{3}{|c|}{ Marginal value on regional tanker deliveries } \\
\hline$\pi_{f, r, s}$ & \multicolumn{3}{|c|}{ Marginal value on pipeline deliveries, or competitive pipeline prices } \\
\hline \multicolumn{2}{|c|}{$P_{f, s}-\sigma_{f, r, s} \leq 0$} & $\perp e_{f, r, s} \geq 0$ & $(\mathrm{~A} 2.1)$ \\
\hline \multicolumn{2}{|c|}{$\pi_{f, r, s}-\alpha_{a, f, r, s} \leq C_{a, f, r, s}$} & $\perp q_{a, r, s} \geq 0$ & $(\mathrm{~A} 2.2)$ \\
\hline \multicolumn{2}{|c|}{$\sigma_{f, r, s}-\left.\rho_{r, s}^{l i q} N_{s}\right|_{f=C H_{4}}-\pi_{f, r, s} / Y^{i n} \leq O_{f}^{i n}$} & $\perp l_{f, r, s}^{i n} \geq 0$ & $(\mathrm{~A} 2.3)$ \\
\hline \multicolumn{2}{|c|}{$\pi_{f, r, s} Y_{f, r, r}^{\text {pipe }}-\left.\rho_{r, s}^{r e g} N_{s}\right|_{f=C H_{4}}-\varphi_{f, r, s} \leq O_{f}^{\text {out }}$} & $\perp l_{f, r, s}^{\text {out }} \geq 0$ & $(\mathrm{~A} 2.4)$ \\
\hline \multicolumn{2}{|c|}{$\pi_{f, r r, s}-\pi_{f, r, s}-\lambda_{f, r, r r, s} N_{s} \leq O_{f, r, r r}^{p i p e}$} & $\perp t_{f, r, r r, s}^{\text {pipe }} \geq 0$ & $(\mathrm{~A} 2.5)$ \\
\hline \multicolumn{2}{|c|}{$\varphi_{f, r r, s} Y_{f, r, r r}^{t a n k} Y_{f}^{\text {out }}-\sigma_{f, r, s} \leq O_{r, r r}^{t a n k}$} & $\perp t_{f, r, r r, s}^{\operatorname{tank}} \geq 0$ & $(\mathrm{~A} 2.6)$ \\
\hline \multicolumn{2}{|c|}{$\lambda_{r, r r} \leq K_{r, r r}^{p i p e}$} & $\perp u_{f, r, r r, s} \geq 0$ & $(\mathrm{~A} 2.7)$ \\
\hline \multicolumn{2}{|c|}{$\rho_{r}^{l i q} \leq K^{l i q}$} & $\perp f_{r}^{l i q} \geq 0$ & (A2.8) \\
\hline \multicolumn{2}{|c|}{$\rho_{r}^{r e g} \leq K^{r e g}$} & $\perp f_{r}^{r e g} \geq 0$ & (A2.9) \\
\hline
\end{tabular}

The orthogonal complementary pairs derived for each variable of the primal problem (A1), using the dual variables listed in Table A.2, are defined in equations (A2.1) to (A2.9). These are combined with the original primal constraints, (A1.1) to (A1.7), to construct the linear complementary problem (LCP) of the fuel supplier. 
The LCP of the fuel supply sector is combined with the LCP of the power, water and transmission sectors (not shown) that define the exogenous industrial fuel demand $d_{f, r, s}$. We refer to studies by Matar et al. (2015, 2017) and Wogan et al. (2019) for a description of the other industrial sectors included in the KEM. In this structure, different pricing rules can be assigned to the exogenous fuel demand, in addition to regional fuel allocation constraints. This produces an MCP model of the integrated energy sectors under existing regulatory constraints.

We refer to Rioux et al. (2020) for a technical description of how to construct a multisector MCP with price regulation using the extended mathematical programing framework within the general algebraic modeling system.

\section{A.3. Complementarity slackness conditions for the Liberalized price cap scenario}

$$
\begin{array}{ll}
\pi_{f, r, s}-L_{f, r, s} \leq \delta_{f, s} & \perp \varepsilon_{f, r, s} \geq 0 \\
1 \leq \sum_{r} \varepsilon_{f, r, s} & \perp \delta_{f, s} \geq 0
\end{array}
$$

To construct the Liberalized price cap scenario, we introduce complementarity slackness conditions - as defined in (A3.1) and (A3.2) - to the fuel supplier's LCP. We introduce a new variable $\delta_{f, r, s}$ in (A3.1) that represents the maximum difference between the marginal supply value $\pi_{f, r, s}$ and an average long-term marginal production cost coefficient within each region, $L_{f, r, s}$. End-user fuel prices are then set to $\pi_{f, r, s}-\delta_{f, r, s}$. This bounds regional fuel prices to $L_{f, r, s}$ in the region where $\delta_{f, r, s}$ is the largest, but preserves differences between regional prices due to transportation costs and premiums.

Equation (A3.1) is paired with the dual variable $\varepsilon_{f, r, s}$ defined in (A3.2), such that if there is a positive $\delta_{f, s}$, (A3.1) must be binding $\left(\pi_{f, r, s}-L_{f, r, s}=\delta_{f, s}\right)$ in the region with the largest difference. 


\section{Appendix B. Calibration dataproblem}

\section{B.1. Gas production and demand}

In our analysis, fuel production is modeled as linear activities characterized by marginal supply cost and assuming constant production capacity.

We use a simple linear representation of upstream production activities that includes both oil and gas. The capacity and cost of producing crude oil and sales gas (methane) are calibrated to the 2018 Rystad UCube database for each country. This includes short-term production costs of non-associated gas and crude oil and associated gas production. Projections of future production capacities and costs are also extracted from Rystad and can be used to run dynamic scenarios (not presented in the current analysis).

We account for seasonality in gas demand based on the characterization of load curves used in the power transmission model. Seasons are characterized as Summer, Fall/Spring and Winter. All other industrial demand is treated as fixed. Gas demand is calibrated to publicly available reports from the GCC countries and reports accessed through a subscription to Facts Global Energy, Middle East \& North Africa Gas.

\section{B.2. Pipeline and LNG tanker networks}

The average pipeline capital cost of $\$ 0.005 / \mathrm{MMBtu} / \mathrm{km}$ for onshore pipelines (Table 3 ) is obtained from an average Arab pipeline project with a diameter of at least 36 inches, which is published by The World Bank (2013). This is doubled for onshore pipelines. The average operating costs are $\$ 0.01 / 1000 \mathrm{~km}$, with a loss rate (internal use for compressors) of $0.003 \% / \mathrm{km}$. The lifetime of pipeline projects (for discounting purposes) is set at 35 years.

For LNG processing, we use data by Songhurst (2019) on the capital and operating costs of floating liquefaction and regasification facilities. We assume liquefaction losses (internal consumption) of $10 \%$. Operating costs and processing losses for LNG imports are derived from Tavares et al. (2018).

For LNG tanker transport, we use the estimates of tanker charter and fuel costs derived from the values reported by Timera Energy (2018). These are used to estimate the long-term marginal costs of using LNG tankers for trade within the GCC.

The LNG shipping opex is based on values reported by Timera Energy (2018) and includes tanker charter costs. This study does not explicitly model LNG tanker capacity stocks or investments. This ensures that the model captures the relative economic value of fixed pipeline versus more flexible LNG tanker shipments. ${ }^{4}$ Pipeline transportation losses reflect the internal energy consumption (gas shrinkage) from powering compressors along the pipeline. LNG tanker losses reflect the boil-off from LNG tanker containers at roughly $0.1 \%$ per day, traveling at an average speed of 15 knots.

Appendix B provides a list of inputs for the power and water sector modules, including available generation technologies, their heat rates, and fixed and variable costs. Conventional generation technologies include 
steam turbines (ST), gas turbines (GT), combined cycle gas turbines (CC), and nuclear and coal-fired units. Each unit can also be configured as a water cogeneration (Co) unit using available thermal desalination technologies detailed in the Appendix. Renewable technologies include PV, concentrated solar power (CSP) and wind. Renewable resources' profiles are estimated using station data across the Arab peninsula, as reported by Matar et al. $(2017,2015)$. The solar calculator for the UAE developed by the Masdar institute is also used (Tuomiranta et al. 2017).

Table B.1. Annual interregional pipeline capacities.

\begin{tabular}{c|c} 
From-To & Volume (QBtu) \\
\hline $\begin{array}{c}\text { Qatar to UAE (TAQA) } \\
\text { UAE (TAQA) to (FEWA) }\end{array}$ & 0.80 \\
\hline UAE (FEWA) to OMN & 0.74 \\
\hline $\begin{array}{l}\text { KSA (East) to (Cent) } \\
\text { KSA (Cent) to (West) }\end{array}$ & 3.60
\end{tabular}

Countries: Kingdom of Saudi Arabia (KSA), United Arab Emirates (UAE). Regions: Abu Dhabi (TAQA), Dubai (DEWA), Fujairah (FEWA) and Sharjah (SEWA).

Source: KEM.

Table B.2. Annual liquefaction, regasification, and pipeline capacities in million tonnes per annum (MMTPA).

\begin{tabular}{l|c|c}
\multicolumn{1}{c|}{ Country } & Liquefaction (MMTPA) & Regasification (MMTPA) \\
\hline Bahrain & - & 9 \\
\hline Kuwait & - & 9.6 \\
\hline Oman & 10.8 & - \\
\hline Qatar & 77.4 & - \\
\hline UAE & 8.4 & 10.8
\end{tabular}

Source: Global Gas \& Oil Network (2020). 
Table B.3. Pipeline and tanker transportation distances. Since the table is symmetric we only list values below the diagonal.

\begin{tabular}{|c|c|c|c|c|c|c|c|c|c|c|c|c|}
\hline \multirow{2}{*}{$\begin{array}{l}\text { Legend } \\
\text { Country }\end{array}$} & \multicolumn{4}{|c|}{ Maritime tanker or subsea pipe } & \multicolumn{3}{|c|}{ Onshore pipe } & \multicolumn{5}{|c|}{ Maritime tanker or onshore pipe } \\
\hline & & $\mathrm{BAH}$ & KUW & OMN & QAT & KSA & KSA & KSA & KSA & UAE & UAE & UAE \\
\hline & Region & & & & & CENT & EAST & SOUT & WEST & TAQA & DEWA & FEWA \\
\hline \multicolumn{13}{|l|}{ Bahrain (BAH) } \\
\hline Kuwait (KUW) & & 450 & & & & & & & & & & \\
\hline Oman (OMN) & & 1000 & 1300 & & & & & & & & & \\
\hline Qatar (QAT) & & 250 & 600 & 850 & & & & & & & & \\
\hline \multirow{4}{*}{$\begin{array}{l}\text { Saudi Arabia } \\
\text { (KSA) }\end{array}$} & CENT & & & & & & & & & & & \\
\hline & EAST & 160 & 400 & 1000 & 400 & 400 & & & & & & \\
\hline & SOUT & 4000 & 4500 & 3000 & 4000 & & 1700 & & & & & \\
\hline & WEST & 4500 & 5000 & 3500 & 4500 & 900 & 2200 & 650 & & & & \\
\hline \multirow{4}{*}{$\begin{array}{l}\text { United Arab } \\
\text { Emirates (UAE) }\end{array}$} & TAQA & 450 & 850 & 650 & 500 & & 700 & 1500 & 4900 & & & \\
\hline & DEWA & 500 & 850 & 575 & 750 & & 600 & 4200 & 4850 & 120 & & \\
\hline & FEWA & 550 & 850 & 500 & 450 & & 850 & 4000 & 4700 & 250 & 130 & \\
\hline & SEWA & & & & & & & & & 220 & 100 & 140 \\
\hline
\end{tabular}

Countries: Kingdom of Saudi Arabia (KSA), United Arab Emirates (UAE), Kingdoms of Bahrain (BAH), Kuwait (KUW), Oman (OMN) and Qatar (QAT). Regions: Abu Dhabi (TAQA), Dubai (DEWA), Fujairah (FEWA) and Sharjah (SEWA). Source: KEM.

The existing pipeline capacities are listed in Table B.1, while installed liquefaction and regasification units are presented in Table B.2. Table B.3 shows the distances used to configure the regional gas grid. When calibrating the model, we enforce the following Dolphin pipeline gas contracts: 0.64 QBtu from Qatar to UAE and 0.07 QBtu from UAE to Oman. After running the reference scenario, we also set the following lower bounds on tanker shipment: 0.056 QBtu from Qatar to Kuwait and 0.021 QBtu from Oman to Kuwait. However, these constraints are removed when running the counterfactual scenarios described in our numerical analysis of the GCC gas grid, assuming that members' LNG tanker shipments within the GCC are not subject to long-term contracts. Nevertheless, as we discuss in the main text, we do investigate a scenario in which Qatar secures a 3 MMTPA LNG contract with Kuwait as the major LNG importer in the region. 


\section{B.3. Power and water sector data}

Table B.4 to Table B.6 provide all the generation technologies and calibration coefficients (e.g., costs) of the power and water (desalination) sectors. These are used to calibrate the corresponding modules of KEM. They include steam turbines (ST), gas turbines (GT), combined cycle gas turbines (CC), and nuclear fuel generation technologies, with renewables including photovoltaic (PV), concentrated solar power (CSP) and wind. We use a $6 \%$ discount rate when calculating the annualized investment costs during the expected lifetime of the project, as in Matar et al. (2017).

Table B.5 provides the gain output ratio (GOR) and internal electricity consumption rate of standalone multiple effect distillation (MED) and multi-stage flash distillation (MSF). The GOR values are used to calculate the internal fuel consumption while accounting for boiler efficiency and the energy content of the generated steam. Both MED and MSF plants can be combined with ST, GT or CC units to form power and water cogeneration (Co) units with specific PWRs, as listed in Table B.6. This includes cogeneration units with variable PWR (CoV).

Table B.4. Power plant costs, efficiency and expected lifetime.

\begin{tabular}{l|c|c|c|c|c} 
Plant type & $\begin{array}{c}\text { Capital cost } \\
\mathbf{( \$ / K W )}\end{array}$ & $\begin{array}{c}\text { Fixed cost } \\
\mathbf{( \$ / K W )}\end{array}$ & $\begin{array}{c}\text { Variable cost } \\
\text { (non-fuel) } \\
(\mathbf{\$} / \mathbf{M W h})\end{array}$ & $\begin{array}{c}\text { Net thermal } \\
\text { efficiency \% }\end{array}$ & Lifetime years \\
\hline Steam Turbine (ST) & 1026 & 11.2 & 1.87 & $37 \%$ & 30 \\
\hline Gas Turbine (GT) & 882 & 11.2 & 4.56 & $30 \%$ & 25 \\
\hline Combined Cycle GT (CC) & 1032 & 12.4 & 3.76 & $50 \%$ & 30 \\
\hline Conversion GT to CC & 240 & 12.4 & 4.33 & $42 \%$ & 20 \\
\hline Nuclear & 5288 & 68.8 & 2.56 & $33 \%$ & 35 \\
\hline Photovoltaic (PV) & 1250 & 9 & - & & 25 \\
\hline $\begin{array}{l}\text { Concentrated Solar Power } \\
\text { (CSP) }\end{array}$ & 5204 & 70 & 3.08 & & 30 \\
\hline Wind & 1400 & 35 & - & & 20
\end{tabular}

Source: KEM.

Table B.5. Water plant costs, gain output ratio (GOR) energy consumption and expected lifetime. Cost are in $\$$ per cubic meter per day $\left(\mathrm{m}^{3} /\right.$ day) or thousand cubic meters $\left(\mathrm{Mm}^{3}\right)$.

\begin{tabular}{|c|c|c|c|c|c|}
\hline & $\begin{array}{l}\text { Capital cost } \\
\left(\$ / \mathrm{m}^{3} / \text { day }\right)\end{array}$ & $\begin{array}{l}\text { Fixed cost (\$/ } \\
\text { m }^{3} / \text { day) }\end{array}$ & $\begin{array}{l}\text { Variable non- } \\
\text { fuel }\left(\$ / \mathrm{Mm}^{3}\right)\end{array}$ & $\begin{array}{l}\text { GOR; energy } \\
\text { use }\left(\mathbf{k w h} / \mathrm{m}^{3}\right)\end{array}$ & Lifetime years \\
\hline $\begin{array}{l}\text { Multiple effect distillation } \\
\text { (MED) }\end{array}$ & 1485 & 33.0 & 80 & $10 ; 2$ & 30 \\
\hline $\begin{array}{l}\text { Multi-stage flash distillation } \\
\text { (MSF) }\end{array}$ & 2104 & 33.0 & 80 & $8 ; 3$ & 30 \\
\hline $\begin{array}{l}\text { Saltwater reverse osmosis } \\
\text { (SWRO) }\end{array}$ & 2723 & 48.0 & 100 & $-; 5$ & 25 \\
\hline
\end{tabular}

Source: KEM. 
Table B.6. Power to water ratio (PWR) and net thermal efficiency of water cogeneration plants. PWR reported in MW per million gallons per day (MIGD).

\begin{tabular}{lcl} 
& PWR (MW/MIGD) & Efficiency (\%) \\
\hline ST Co (MSF) & Fixed PWR & \\
\hline GT Co (MSF) & 5 & 0.23 \\
\hline CC Co MED & 8 & 0.28 \\
\hline CC Co MSF & 10 & 0.42 \\
\hline & 16 & 0.42 \\
\hline ST CoV & Variable PWR (minimum) & 0.28 \\
\hline GT CoV & 10 & 0.28 \\
\hline CC CoV (MED) & 8 & 0.45 \\
\hline CC CoV (MSF) & 12 & 0.45
\end{tabular}

Steam cogeneration (ST Co), gas turbine cogeneration (GT Co), combine cycle cogeneration (CC Co), variable cogeneration (CoV), multiple-effect distillation (MED), multi-stage flash (MSF). Source: KEM.

Table B.7. Power and water (cogeneration capacities) in gigawatts (GW).

\begin{tabular}{|c|c|c|c|c|c|c|}
\hline Plant Type & KSA & UAE & QAT & KUW & BAH & OMN \\
\hline ST & 29.61 & & & 1.20 & & \\
\hline GT & 33.15 & 5.70 & 1.25 & & 0.71 & 1.42 \\
\hline $\mathrm{CC}$ & 16.03 & 2.38 & 2.01 & 2.30 & 0.95 & 8.05 \\
\hline PV & 0.02 & 0.51 & & 0.13 & & 0.10 \\
\hline ST Co (MSF) & 4.96 & 2.23 & & & & \\
\hline GT Co (MSF) & 0.20 & 0.00 & 1.67 & & & \\
\hline CC Co MED & 3.44 & 5.00 & & & & \\
\hline CC Co MSF & 2.12 & 13.34 & 4.51 & 2.30 & 1.03 & 0.47 \\
\hline ST CoV & 2.27 & & & 8.97 & & \\
\hline GT CoV & & & & 4.80 & & \\
\hline CC COV MED & 2.23 & & & & & \\
\hline CC CoV MSF & 0.53 & & & & & \\
\hline
\end{tabular}

Steam turbine (ST), gas turbine (GT), combined cycle GT (CC), photovoltaic (PV), steam cogeneration (ST Co), gas turbine cogeneration (GT Co), combine cycle cogeneration (CC Co), variable cogeneration (CoV), multiple-effect distillation (MED), multi-stage flash (MSF). Source: KEM 
Table B.8. Standalone water generation capacities in million $\mathrm{m}^{3}$ per day ( $\left.\mathrm{MMm}^{3} / \mathrm{day}\right)$.

\begin{tabular}{l|c|c|c|c|c|c} 
MMm $^{3} /$ day & KSA & UAE & QAT & KUW & BAH & OMN \\
\hline MED & 0.08 & & & & 0.02 & \\
\hline MSF & & & 0.31 & & 0.07 & \\
\hline SWRO & 3.51 & 1.47 & 0.16 & 3.20 & 0.52 & 0.87
\end{tabular}

Source: KEM.

The power transmission submodules of the GCC use the same demand structure and regional breakdown as those used in Wogan et al. (2019). The national grid in the KSA includes the central, eastern, southern and western operating areas. Additionally, the UAE includes the electricity and water authorities of Abu Dhabi (TAQA), Dubai (DEWA), Fujairah (FEWA) and Sharjah (SEWA). The Kingdoms of Bahrain (BAH), Kuwait (KUW), Oman (OMN) and Qatar (QAT) are characterized as a single region.

Demand is organized into eight-hourly load blocks across the seasons (Summer, Spring/Fall, and Winter). These are constructed from hourly load profiles reported by state-owned electricity companies in the years before 2018. They are then re-scaled to reflect the aggregate power generation of each country (Table B.9).

Table B.9. Power and water demand in terawatt hours (TWh) and billion cubic meters (bm³).

\begin{tabular}{l|c|c|c|c|c|c} 
& KSA & UAE & QAT & KUW & BAH & OMN \\
\hline Electricity demand TWh & 339 & 135 & 37 & 75 & 16 & 37 \\
\hline Water demand bm ${ }^{3}$ & 2.00 & 2.01 & 0.55 & 0.61 & 0.24 & 0.24
\end{tabular}

Source: KEM. 
Table B.10. Regional fuel demand (quotas) in 2018 for the power and water sectors and administered fuel prices.

\begin{tabular}{|c|c|c|c|}
\hline Fuel & Country (region) & Price & Quota \\
\hline \multirow{2}{*}{$\begin{array}{l}\text { Crude oil } \\
\text { Million barrels (MMb) }\end{array}$} & KSA & $\$ 6.35 / \mathrm{b}$ & $131.5 \mathrm{MMb}$ \\
\hline & KUW & $\$ 25 / b$ & $7.9 \mathrm{MMb}$ \\
\hline \multirow{2}{*}{$\begin{array}{c}\text { Diesel } \\
\text { Million tonnes (mt) }\end{array}$} & KSA & \$116.8/tonne & $2.856 \mathrm{mt}$ \\
\hline & KUW & \$200/tonne & $0.61 \mathrm{mt}$ \\
\hline \multirow{2}{*}{$\begin{array}{l}\text { Heavy fuel oil (HFO) } \\
\text { Million tonnes (mt) }\end{array}$} & KSA & \$31.82/tonne & $21.42 \mathrm{mt}$ \\
\hline & KUW & \$175/tonne & $8.1 \mathrm{mt}$ \\
\hline \multirow{6}{*}{$\begin{array}{c}\text { Natural gas } \\
\text { Quadrillion British thermal units (QBtu) }\end{array}$} & BAH & \$3.28/MMBtu & 0.249 QBtu \\
\hline & KSA & $\$ 1.25 / \mathrm{MMBtu}$ & 2.226 QBtu \\
\hline & KUW & \$3.9/MMBtu & 0.415 QBtu \\
\hline & OMN & $\$ 3.28 / \mathrm{MMBtu}$ & 0.332 QBtu \\
\hline & QAT & \$1/MMBtu & 0.391 QBtu \\
\hline & UAE & \$2.42/MMBtu & 1.568 QBtu \\
\hline
\end{tabular}

Countries: Kingdom of Saudi Arabia (KSA), United Arab Emirates (UAE), Kingdoms of Bahrain (BAH), Kuwait (KUW), Oman (OMN) and Qatar (QAT). Source: KEM.

The GCC interconnector includes a 1.2 GW trunk line connecting Kuwait, the eastern region of Saudi Arabia, Qatar and the UAE (TAQA). It also has a 0.6 GW branch linking Saudi Arabia to Bahrain. Saudi Arabia's national grid includes the lines of $4.8 \mathrm{GW}$ from EAST to CENT, 1.2 GW from CENT to WEST, 2.5 GW from WEST to SOUTH and $0.25 \mathrm{GW}$ from CENT to SOUTH. The UAE national grid includes $1.15 \mathrm{GW}$ linking TAQA, DEWA and SEWA, $1 \mathrm{GW}$ linking TAQA, SEWA and FEWA, $1.2 \mathrm{GW}$ from DEWA to FEWA, and finally, 0.4 GW linking UAE (FUWA) to Oman, completing the GCC grid. 


\section{Appendix C. Additional scenario results}

Figure C.1. Power sector investments in gigawatts (GW).

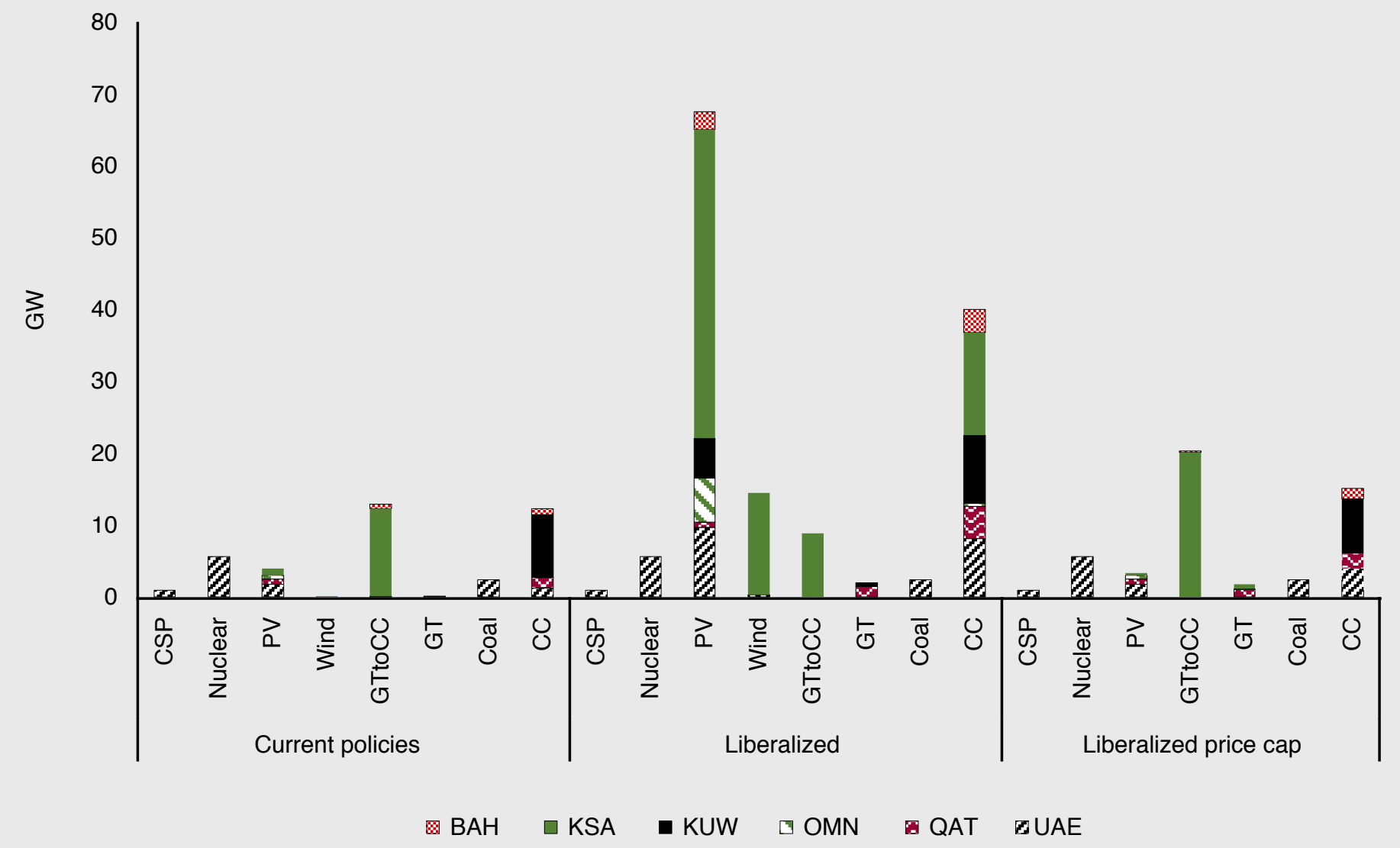

Countries: Kingdom of Saudi Arabia (KSA), United Arab Emirates (UAE), Kingdoms of Bahrain (BAH), Kuwait (KUW), Oman (OMN) and Qatar (QAT). Technologies: Concentrated Solar Power (CSP), photovoltaic (PV), gas turbine (GT), combined cycle gas turbine (CC), GT to CC conversion (GTtoCC). Source: KAPSARC analysis.

Figure C.1 summarizes the cogeneration power sector investments in the Current Policies and Liberalized scenarios. All scenarios show pent-up levels of plant conversions from open cycle to the more efficient combined cycle turbines (GTtoCC) in the Current Policies scenario and more renewables and CC in the Liberalized scenario.

With renewables being more competitive under Liberalized prices (Table 7), PV and wind capacities increase by $35 \mathrm{GW}$ and $5 \mathrm{GW}$, respectively. Furthermore, there is significant investment in more efficient gas fired units. With increased investment in solar and wind generation, existing single-cycle GTs are valued as spinning reserves to balance the intermittency of renewable capacity. The development of the gas grid plays an important role in supporting gas availability as well as the reliability of a regional power grid with increased penetration of intermittent renewables.

The water sector (not shown) also invests in more efficient SWRO units to phase out the use of energy-intensive thermal desalination. This includes approximately 1 and 6.6 million cubic meters of new capacity per day under the Current Policies and Liberalized scenarios, respectively. 
We have not thus far addressed how the gains derived from the expansion of the gas grid might be distributed among the GCC countries and how they impact different sectors. Figure C.2 breaks down the changes in economic value for a given counterfactual scenario when introducing cross-border pipeline investments. The sectors are broken down into fuel production and transport (fuel supply) sectors and other sectors that drive fuel demand, i.e., electricity production, power transmission and water production.

Figure C.2. Breakdown of economic gains from pipeline investments in each counterfactual scenario by country, fuel supply and other demand sectors (electricity, water and power transmission).

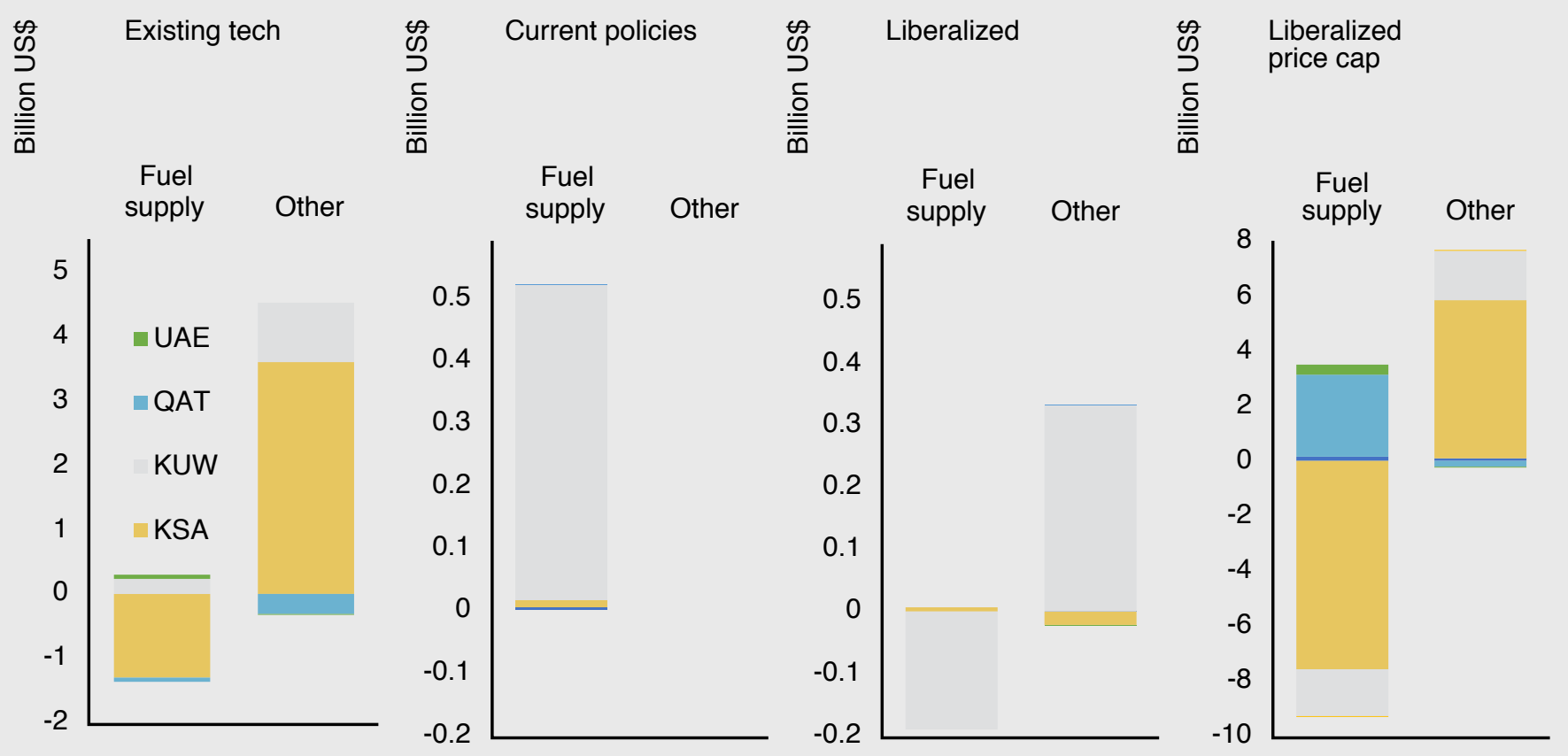

Countries: Kingdom of Saudi Arabia (KSA), United Arab Emirates (UAE), Kingdoms of Bahrain (BAH), Kuwait (KUW), Oman (OMN) and Qatar (QAT). Source: KAPSARC analysis.

How the gains are divided in practice depends on trade agreements among countries as well as sectors, such as the sale of fuel to the electricity and water sectors. In these figures, we assume that all cross-border and inter-sectoral trade is priced at marginal value pricing, while sectoral fuel sales align with the given scenario (administered prices or liberalized) as described in the main text. To facilitate rent sharing, parties could apply alternative agreements. An example is the long-term bilateral trade agreement adopted by the Dolphin pipeline and most TAGP countries in Asia.

Recall that under Existing tech, existing liquid fuel quotas (subject to administered prices) are lifted, and we determine the optimal allocation of gas based on the current technology mix. First, the Other fuel consumption sectors experience a net economic gain from the gas grid expansion in Kuwait and Saudi Arabia. This is due to the increasing accessibility and availability of gas that offsets the cost of more expensive liquid fuel consumption. In Kuwait, the midstream fuel purchases, part of the fuel supply sector, 
Table C.1. Natural gas supply and demand balances in each counterfactual scenario in Quadrillion British thermal units (QBtu).

Country

\begin{tabular}{|c|c|c|c|c|c|c|c|}
\hline Scenario & BAH & KSA & KUW & OMN & QAT & UAE & Total \\
\hline \multicolumn{8}{|l|}{ Current Policies } \\
\hline Production & 697 & 11626 & 2615 & 2156 & 6731 & 4415 & 28240 \\
\hline Demand & 1123 & 6187 & 1832 & 1028 & 1894 & 2970 & 15034 \\
\hline Power and Water & 205 & 3625 & 557 & 293 & 375 & 941 & 5997 \\
\hline Other & 918 & 2562 & 1275 & 735 & 1519 & 2029 & 9038 \\
\hline Imports & 160 & 74 & 150 & 70 & & 222 & 676 \\
\hline Imports Pipeline & 160 & 74 & 150 & 70 & & 216 & 669 \\
\hline Imports Tanker & & & 0 & & & 6 & 6 \\
\hline Exports & 118 & 5693 & 1622 & 1186 & 4752 & 2282 & 15654 \\
\hline Exports Pipeline & 44 & 312 & & & 249 & 71 & 677 \\
\hline Exports Tanker & 74 & 5381 & 1622 & 1186 & 4502 & 2211 & 14977 \\
\hline \multicolumn{8}{|l|}{ Existing Tech } \\
\hline Production & 697 & 11626 & 2615 & 2156 & 6731 & 4415 & 28240 \\
\hline Demand & 1194 & 6147 & 2076 & 1035 & 2058 & 3500 & 16010 \\
\hline Power and Water & 276 & 3585 & 801 & 300 & 539 & 1471 & 6972 \\
\hline Other & 918 & 2562 & 1275 & 735 & 1519 & 2029 & 9038 \\
\hline Imports & 201 & 1722 & 536 & 70 & & 638 & 3168 \\
\hline Imports Pipeline & 201 & 1722 & 536 & 70 & & 638 & 3168 \\
\hline Imports Tanker & 0 & 0 & 0 & & & 0 & 0 \\
\hline Exports & 89 & 6611 & 1622 & 1180 & 4817 & 2185 & 16504 \\
\hline Exports Pipeline & 14 & 745 & & & 2376 & 71 & 3207 \\
\hline Exports Tanker & 74 & 5866 & 1622 & 1180 & 2441 & 2114 & 13297 \\
\hline \multicolumn{8}{|l|}{ Liberalized } \\
\hline Production & 697 & 11626 & 2615 & 2156 & 6731 & 4415 & 28240 \\
\hline Demand & 1068 & 4501 & 1752 & 948 & 1881 & 2437 & 12586 \\
\hline Power and Water & 150 & 1939 & 477 & 213 & 362 & 407 & 3548 \\
\hline Other & 918 & 2562 & 1275 & 735 & 1519 & 2029 & 9038 \\
\hline Imports & 160 & 0 & 212 & 0 & & 11 & 382 \\
\hline Imports Pipeline & 160 & 0 & 212 & 0 & & 0 & 372 \\
\hline Imports Tanker & & & 0 & & & 11 & 11 \\
\hline Exports & 163 & 6469 & 1622 & 1195 & 4739 & 2563 & 16751 \\
\hline Exports Pipeline & 0 & 375 & & & 0 & 0 & 375 \\
\hline Exports Tanker & 163 & 6094 & 1622 & 1195 & 4739 & 2563 & 16376 \\
\hline \multicolumn{8}{|l|}{ Liberalized price cap } \\
\hline Production & 697 & 11626 & 2615 & 2156 & 6731 & 4415 & 28240 \\
\hline Demand & 1106 & 5571 & 1800 & 1040 & 1912 & 2753 & 14183 \\
\hline Power and Water & 188 & 3009 & 525 & 305 & 393 & 724 & 5145 \\
\hline Other & 918 & 2562 & 1275 & 735 & 1519 & 2029 & 9038 \\
\hline Imports & 160 & 1024 & 260 & 0 & & 11 & 1455 \\
\hline Imports Pipeline & 160 & 1024 & 260 & 0 & & 0 & 1444 \\
\hline Imports Tanker & & & 0 & & & 11 & 11 \\
\hline Exports & 135 & 6378 & 1622 & 1112 & 4801 & 2285 & 16333 \\
\hline Exports Pipeline & 61 & 424 & & & 903 & 73 & 1461 \\
\hline Exports Tanker & 74 & 5954 & 1622 & 1112 & 3898 & 2211 & 14872 \\
\hline
\end{tabular}

Source: KAPSARC analysis. 
benefit from a reduction in more expensive maritime LNG shipments and higher export revenues. However, the Saudi fuel supply sector loses value by providing gas to the power and water sectors below the marginal supply value (cost of imports).

Under Current policies, Kuwait's fuel supply sector is the main benefactor from the reduction in cost of importing more expensive LNG. As net exporters, Qatar and Saudi Arabia do not gain or lose significantly and may seek out different trade structures to share the gains secured by Kuwait.

In the Liberalized scenario, gains secured by the fuel supply and other sectors nearly balance out, with marginal gains for Kuwait from cheaper gas purchasing costs for other fuel consuming sectors. When applying a cap on the integrated gas prices (\$4/MMBtu max in Qatar), Kuwaiti and Saudi fuel-consuming sectors benefit from cheaper gas prices by investing in new cross-border pipelines. The pipelines also help offset capital-intensive power sector investments including expansion of the GCC interconnector and power trade. However, the upstream and midstream sectors of Kuwait and Saudi Arabia face increased costs from trading gas, which counteract out these gains. Meanwhile, Qatar (and to a lesser extent, the UAE) increases rents from the export of natural gas both within and outside the GCC. 
Notes

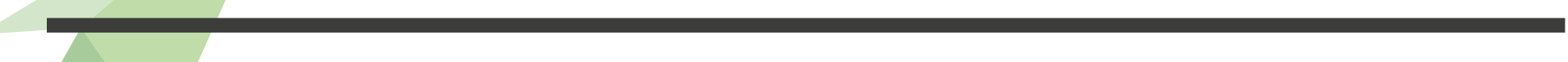




\section{Notes}




\section{About the Authors}

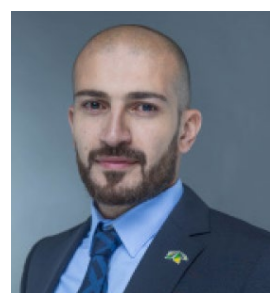

\section{Rami Shabaneh}

Rami is a senior research associate whose focus is global gas and liquids markets. Rami has more than 13 years of research and industry experience in analyzing energy markets and energy policy. Before joining KAPSARC, Rami worked at Cenovus Energy as a market fundamentals analyst; there, he provided analytic support on specific issues affecting North American gas, natural gas liquids and condensate markets. His work directly supported the company's hedging strategies. Before working at Cenovus Energy, Rami spent three years as an integral member of the fuels and power research team at the Canadian Energy Research Institute. He holds an M.Sc. in sustainable energy development and a B.Sc. in actuarial science from the University of Calgary.

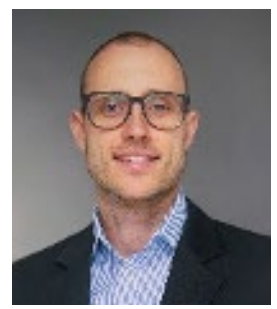

\section{Bertrand Rioux}

Bertrand is a KAPSARC research fellow who specializes in energy market design and energy systems modeling. He holds a master's degree from KAUST with a specialization in computational fluid dynamics and a master's degree in digital currency from the University of Nicosia.

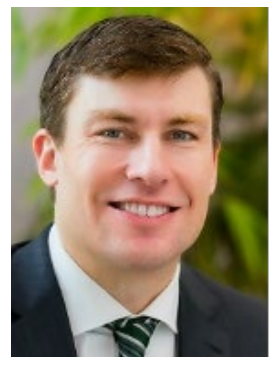

\section{Steve Griffiths}

Steve is senior vice president of research and development and professor of practice at Khalifa University of Science and Technology in the United Arab Emirates. He specializes in energy system policy and strategy, with focus on the Middle East and North Africa. He holds a Ph.D. in chemical engineering from the Massachusetts Institute of Technology (MIT) and an MBA from the MIT Sloan School of Management.

\section{About the Project}

Natural gas is a key enabler of energy diversification and increasing industrialization in the GCC. After the significant drop in oil prices in 2014-15, there was an apparent shift by GCC members to increase their gas utilization, with many countries setting ambitious targets for the development of their abundant non-associated gas reserves. This project aims to identify the opportunities for and challenges of gas development and coordination in Saudi Arabia and other GCC countries. 
INAPSARC

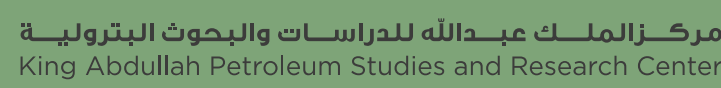

www.kapsarc.org 